\title{
Las teorías democráticas de la autodeterminación y secesión*
}

\author{
Ignacio María Beobide Ezpeleta \\ Catedrático de Derecho Constitucional \\ Universidad de Deusto
}

Recibido: 18.06 .07

Aceptado: 10.11 .07

\begin{abstract}
Resumen: Este trabajo analiza las teorías democráticas o plebiscitarias de la autodeterminación y secesión. En primer lugar se exponen las versiones de distintos autores defensores de tales teorías con la finalidad de captar cuanto les es común, el consentimiento individual como fundamento del 'derecho moral' a la autodeterminación y secesión, y las diferencias, es decir, las condiciones, notablemente distintas, que cada autor exige para el ejercicio de tal derecho. En segundo lugar se recoge el análisis crítico que buena parte de la doctrina y el propio autor del trabajo hacen de la teoría democrática. Las conclusiones destacan, de manera especial, la debilidad de tales teorías desde el punto de vista teórico y metodológico.
\end{abstract}

Palabras clave: Autodeterminación, secesión, Estado, democracia.

Abstract: This paper analyses the democratic theories of self-determination and secession. The first section summarises the most relevant versions of these theories proposed by several authors to identify (a) the common element: the individual consent as the basis of «moral right» to self-determination and secession, and (b) the conditions, notably different, that each author contemplates for the application of this right. The second section undertakes a critical review of these theories. Finally, the conclusions highlight the weaknesses of these theories from the theoretical and methodological viewpoint.

Key words: Self-Determination, Secession, State, Democracy.

Sumario: I. Introducción. II. Algunas precisiones conceptuales. III. La defensa de la autodeterminación para la secesión en la teoría democrática. El principio de asociación política voluntaria basada en el derecho individual de libre asociación. IV. Crítica de la teoría democrática: 1 . Teoría y método. 2. Aportación de la teoría democrática al Derecho Internacional. 3. Filosofía Política y Derecho Internacional. V. Conclusiones.

\footnotetext{
* Agradezco la colaboración prestada por los profesores de la Facultad de Derecho de la Universidad de Deusto, Iciar Basterretxea y Luis Gordillo, que, a través de sus correcciones, críticas y observaciones, han hecho posible la mejora de las primeras versiones de este trabajo.
} 


\section{INTRODUCCIÓN}

El siglo XX ha visto multiplicarse el número de Estados. El aumento del número de miembros de las N.U. ha pasado de 51 miembros en el momento de su creación en 1945 a 149 en 1984 y a 191 en la actualidad. El salto de 51 a 149 miembros se debió, fundamentalmente, al proceso de descolonización, y los cambios de los últimos quince años se han debido a la secesión, entendida en un sentido amplio (Kohen, 2006: 2). Si, como hacen algunos autores, la descolonización se entendiera, también, como un tipo de secesión, su papel en la formación de la organización internacional sería francamente enorme. Sin embargo, las matizaciones que se deben hacer al concepto de secesión rebajan radicalmente esta, en principio, impresionante imagen.

En la actualidad, los políticos de minorías nacionales, reales o inventadas, de grupos identitarios, de grupos perseguidos y sometidos a la injusticia o de grupos radicales democráticos suelen utilizar, sin duda alguna, este hecho de la proliferación de Estados para transmitir la convicción de la posibilidad y, sobre todo, de la inevitabilidad de lograr el apetecido bien del Estado, al que supuestamente tendrían sus grupos sociales un claro derecho. Hasta suele ser costumbre fijar fecha para tan imprescindible acontecimiento, como ocurre entre nosotros.

También parece que el crecimiento del club internacional de Estados ha influido en el trabajo de bastantes académicos para proponer la secesión como una solución a determinados problemas sociales y políticos actuales. Se daría de este modo una confluencia entre el proceso histórico secesionista, interpretado como el signo de los tiempos, las demandas actuales de los grupos sociales independentistas y, de manera especial, de políticos y gobiernos regionales, y el trabajo de los teóricos con los argumentos de la globalización, la identidad cultural, la homogeneidad, la libertad de asociación, el fin del Estado-Nación y lo que Darhrendorf llama la 'glocalización' en referencia a la invención del localismo de las «regiones homogéneas» y a la salida, desde los Estados nacionales hacia otros centros de poder, de decisiones políticas fundamentales (Darhendorf, 2002: 31-33).

Buena parte de lo que se escribe en el campo de las ciencias sociales gira en torno a la autodeterminación, la secesión, el autogobierno, el Estado multinacional, el Estado étnico-homogéneo en cuanto instrumentos y alternativas al Estado-Nación. Brian Barry califica de sabihondos y analfabetos en historia y sociología a los multiculturalistas que consideran natural que el descontento social se oriente hacia el fundamentalismo, nacionalismo y el chovinismo cultural, como si fuera algo inevitable. Y, aunque este juicio y otros, como el afirmar que 'la literatura del multiculturalismo no merece el tiempo ni el esfuerzo de escribirla' o que los que no escriben sobre él es porque tienen otros temas más interesantes que escribir (Barry, 2001: 4.6), puedan parecer a alguien un tanto exagerados, lo cierto es que se observa una notable deficiencia argumentativa en la defensa de la autodeterminación y 
secesión, incluso, en aquellos que no defienden el multiculturalismo, como se podrá ver en estas páginas ${ }^{1}$.

Sorprende, ciertamente, que la autodeterminación para la secesión ocupe tanto espacio en los estudios académicos por encima del análisis de las razones que hay a favor de la solidaridad, la igualdad, la colaboración, o, como dicen algunos, utilizando un nombre maldito para los secesionistas, el unionismo. El pensamiento filosófico que se va a analizar en este trabajo tiene, como dice Norman, una teoría de la justificación de la ruptura del Estado, pero no de las razones de la unidad y estabilidad del Estado que sirven para garantizar los bienes de la justicia liberal (Norman, 1998: 40). Ello supone una desviación de lo que debería ser, siguiendo un razonamiento muy al gusto de los defensores de la secesión, el razonamiento moral, un objeto de análisis científico más valioso y necesario como sería el tema de la cooperación entre las personas y los grupos sociales. La reflexión sobre la secesión, al menos en lo que se refiere al mundo occidental democrático, parece que debería quedar para casos, más bien, residuales o meramente académicos. La cooperación y la solidaridad son las formas suaves y más tolerables de la igualdad revolucionaria y, aunque no tienen el valor de la igualdad, son un fundamento básico del Estado democrático y de la democracia, que no pueden faltar en la búsqueda de las alternativas al Estado Nacional. Parece mucho más racional defender y teorizar sobre la unidad, la solidaridad y la cooperación como garantías permanentes de la paz y de la libertad, dejando la separación para lo que parezca imposible de mantenerse unido, si es que realmente se da el caso, que teorizar sobre lo que, en principio, se presenta como menos valioso - la secesión- y verse obligado a hacer continuas excepciones a ella, porque, de lo contrario, se negarían valores esenciales. Como dice Coppieters (2003: 279), los estudios sobre la secesión deben compararse con factores tales como la fraternidad y la mutua necesidad que permiten a los Estados mantenerse unidos o inspirar la creación de nuevas unidades políticas. No es, por todo ello, exagerado afirmar que la focalización de los análisis teóricos sobre la secesión en lugar de la cooperación sugieren una deficiente concepción moral (Bishai, 1998: 94).

La secesión se puede estudiar desde varios puntos de vista, dando lugar, así, a diferentes metodologías de análisis. Cabe destacar el enfoque jurídico, el político y el moral. El objetivo de este trabajo es analizar las teorías que

\footnotetext{
${ }^{1}$ Brian Barry (1997: 349) tiene, también, un comentario crítico contra algunos sectores del mundo intelectual al escribir que «todo este asunto plantea una cuestión sobre la sociología del mundo erudito que me intriga: ¿cómo es que alguien con el tipo de intelecto capaz de producir 'Justice as Reversibility' pudo ser tomado en serio alguna vez? Supongo que cualquier respuesta adecuada tendría que arrojar una luz poco favorable sobre la psicología social como disciplina erudita. Pero supongo que otro factor que se habría de invocar en la explicación tendría que ser el llamado 'efecto halo' -la presunción de que un profesor de la Universidad de Harvard no puede ser incapaz de pensamiento coherente».
} 
legitiman o justifican la secesión desde el punto de vista moral, insistiendo, especialmente, en las razones o argumentos que utilizan para fundamentar lo que llaman, incorrectamente, el derecho moral a la secesión de un grupo social y de un territorio de un Estado.

Una clasificación de las teorías de la secesión, de acuerdo con el tipo de argumentos seguidos para justificar la secesión, y no obstante la variedad de terminología utilizada, las integra en tres grupos: teorías asociativas, basadas en el principio de la voluntad de los miembros del grupo, teorías nacionalistas, basadas en el principio de nación o pueblo, y teorías basadas en la reparación de injusticias (teorías del derecho remedial o reparador). Las dos primeras clases de teorías integran el grupo denominado de 'teorías del derecho primario' frente al tercer tipo, que justifica la secesión como instrumento, y consecuencia, a la vez, de remediar las injusticias cometidas por el Estado. En la breve descripción que hago a continuación incluyo una cuarta basada en la democracia comunicativa, que no goza de tanto fervor como las anteriores, pero que cuenta con el apoyo de renombrados teóricos.

Las teorías asociativas no defienden que los grupos han de tener determinadas características prepolíticas, como lo hacen las teorías nacionalistas, ni exigen injusticias demostrables, como las teorías del principio remedial, para tener derecho a la secesión. Basta con que los miembros del grupo participen del mismo deseo de tener su propio Estado. Los conceptos de común cultura, historia o etnia son ajenos a estas teorías. Por el contrario, la decisión de formar una comunidad propia se fundamenta en la elección política voluntaria de los miembros del grupo. Son los miembros del grupo los que libremente escogen asociarse juntos en una comunidad política propia. Por tanto, el derecho de secesión se fundamenta en el derecho de asociación política. El derecho de secesión no es más que una de las aplicaciones del derecho de asociación.

Se trata, pues, de una teoría individualista y procedimental, ya que el derecho de autodeterminación para la secesión se fundamenta a partir de las libertades políticas de los ciudadanos y a partir del consentimiento mayoritario de los miembros del territorio secesionista expresado según criterios democráticos. En este caso no cuentan los argumentos nacionales, y, si bien las injusticias como la opresión política o explotación económica son razones secundarias, el fundamento determinante, haya o no injusticias, es el consentimiento individual de los ciudadanos. Estas teorías pretenden hacer coincidir el derecho de autodeterminación con la autodeterminación de los ciudadanos de un territorio no delimitado por fronteras étnicas o culturales. Por tanto, la secesión se justifica, incluso, en el caso de un Estado 'justo', es decir, un Estado que respete los derechos individuales, los derechos humanos y no discrimine con su política a las minorías.

Las teorías nacionalistas -también llamadas teorías de la autodeterminación nacional- defienden que los grupos que poseen unas características prepolíticas son los que tienen el derecho a formar una asociación política Su 
existencia es independiente de cualquier asociación formada por sus miembros. Estos grupos son la nación o pueblo y para estas teorías nación o pueblo es todo grupo social que tenga, en común, cultura, historia, lengua, conciencia de su diferencia y, tal vez, una aspiración compartida de formar una comunidad política. Las naciones o pueblos existen sin necesidad de organización, relación o pretensión políticas del grupo. El principio nacionalista es el fundamento del supuesto derecho a la secesión y, por ello, no hace falta recurrir a la injusticia sufrida para legitimar la secesión, aunque, de hecho, se utiliza, también, como argumento ${ }^{2}$. Según esto, las naciones disfrutan de un derecho primario de autodeterminación que lleva consigo que, cuando forman minorías nacionales, tienen derecho a crear su propio Estado mediante la secesión. W. Wilson y el Tratado de Versalles están detrás de esta disparatada concepción, que defiende que las fronteras de los Estados deben coincidir en lo posible con las fronteras naturales de estas comunidades étnicas y culturales.

A pesar de que teóricos nacionalistas defiendan este principio de manera radical, como un derecho puro y simple, son pocos, hoy en día, entre los liberales nacionalistas los que así lo asumen. Más bien, establecen que las naciones no tienen tal derecho a menos que se dé una serie de condiciones indispensables e, incluso, niegan el derecho de autodeterminación nacional para sustituirlo por una concepción multinacional del Estado de Derecho. Consideran que sería impracticable y peligroso para el equilibrio mundial aplicar en sentido estricto el principio, cuando en el mundo conviven 5000 grupos étnicos y nacionales. Pero, si el Estado se comporta injustamente con las minorías nacionales o no reconoce suficiente autonomía política, entonces consideran que estaría justificada la secesión, lo cual supone un acercamiento a las teorías de la justa causa. Se puede hablar, pues, de una interpretación moderada de una concepción substancial de la autodeterminación, según la cual son los pueblos y las naciones los que tienen el derecho y los que se autodeterminan, bien para la autonomía política bien para la secesión. La teoría es, en definitiva, comunitaria y substancial.

Como luego se verá, la Filosofía Política ha seguido un camino de desarrollo del derecho a la autodeterminación distinto del que se observa en el Derecho Internacional, donde, a partir de la segunda guerra mundial, la con-

\footnotetext{
${ }^{2}$ Birch matiza que el recurso a la injusticia, más bien inventada que real, es una necesidad de todo nacionalismo, ya que sólo el 'testarudo nacionalista', romántico, pero no racionalista, argumenta de forma nacionalista. El apoyo popular requiere otros argumentos y aquí juegan un importante papel las supuestas injusticias o los beneficios que traerá la creación de un nuevo Estado (1989: 67). Esta afirmación de Birch se confirma con los análisis empíricos, por ejemplo, del nacionalismo del Partido Nacionalista Vasco, que en su pretensión de captación del voto ha llegado a utilizar menos del 7\% de la campaña electoral en el desarrollo del argumento nacionalista. Vide mi monografía «Prensa y Nacionalismo vasco. El discurso de legitimación nacionalista», Universidad de Deusto, Bilbao, 2003, p. 23.
} 
cepción es esencialmente territorial y no étnica. Fuera del caso de las colonias, es la doctrina de la soberanía del Estado con su unidad nacional, integridad territorial, jurisdicción exclusiva y no intervención la que determina la interpretación del derecho de autodeterminación externa e interna.

Las teorías basadas en el principio remedial o reparador de la injusticia -también llamadas teorías de la justa causa- tienen alguna semejanza con las teorías del derecho a la revolución, como la tan conocida y celebrada teoría de Locke, aunque se diferencian en que éstas no pretenden derrocar a un gobierno tiránico de un Estado, sino cortar, mediante la secesión del territorio, el control del gobierno sobre una parte de éste, cuyos ciudadanos son tratados injustamente. Se trata de teorías que justifican la secesión como respuesta a una tiranía selectiva, cuando la revolución no es prácticamente posible, y parece, así, ser algo intachable y relativamente moderado. Tanto en la revolución como en la secesión, el derecho se entiende como derecho de las personas sometidas a la autoridad política a defenderse de las injusticias como último recurso. El derecho de secesión ha de entenderse como un derecho general y sólo existe cuando el grupo ha sufrido injusticia. No se niega que pueda haber casos especiales de derecho de secesión donde no haya habido injusticias, basados, por ejemplo, en que así lo establezca la Constitución del Estado. Pero, el derecho general sólo lo reconocen estas teorías como instrumento reparador de la injusticia (por ejemplo, violación permanente de los derechos humanos básicos), lo que quiere decir que no existe derecho general a la secesión de un Estado justo.

Estas teorías distinguen, también, entre la parte substancial y la parte procedimental. Para hacer la secesión son necesarias razones morales substanciales -las injusticias-, no la mera voluntad de una mayoría. Según esto, no existe un derecho primario a la secesión, cosa que, también, reconocen los liberales nacionalistas, sino razones morales substanciales a las que se han de unir necesariamente instrumentos institucionales para aplicarlas. Los instrumentos institucionales constituyen el elemento procedimental y han de entenderse, por otra parte, de forma esencialmente jurídica, bien a través de fijar principios y procedimientos claros de secesión en el orden internacional o bien a través de la constitucionalización del derecho a la secesión. No se trata de fomentar la secesión, sino de prevenir y de regular de antemano sus efectos.

Una variante de las teorías de la causa justa $-\mathrm{y}$ que, en cierto modo, podría considerarse como un cuarto tipo de teorías- es la concepción deliberativa de la secesión. Según ésta, la secesión necesita para su justificación razones morales substanciales y mecanismos institucionales. Ahora bien, las razones morales no pueden ser determinadas de antemano, como en el caso de las teorías de la causa justa, sino que son los actores participativos en la deliberación los que hacen valer las razones y los que han de convencer a la opinión pública de su validez como causa justa. Y, así, puede ser cualquiera de las causas de las teorías de la causa justa u otras, como, por ejemplo, las reivindicaciones autonomistas de los grupos culturales o étnicos. 
En cuanto a los instrumentos institucionales, éstos no tendrán naturaleza jurídica, sino política, es decir, democrática y deliberativa. No correspondería al Derecho dictar las reglas de la secesión, sino a los ciudadanos partícipes en las deliberaciones democráticas, transparentes e igualitarias. La teoría deliberativa contrapone la versión jurídica de la secesión elaborada por los 'elegidos', sean jueces o constitucionalistas, con la democrática deliberativa. Las teorías deliberativas no rechazan el papel y la legitimidad del Derecho en relación con la secesión y no defienden que sus tesis son capaces de solucionar todos los casos de secesión, sino, simplemente (y esto rebaja mucho su pretensión), consideran que hay ocasiones en que la democracia deliberativa puede ser más eficaz, por ser más flexible, que las normas rígidas del Derecho Constitucional o Internacional y, por otra parte, su aplicación no haría ni demasiado fácil, ni demasiado difícil la secesión (Buchanan, 1998: 230-234; Norman, 1998: 35-43; Courtois, 2004: 812-815; 832-834; Moore, 1998: 4-8; 2006: 59-60; 63-64; 66-67 y 78)

Todas estas teorías no hay que interpretarlas como si fueran absolutamente distintas unas de otras. Ciertamente hay diferencias substanciales entre ellas, pero también hay coincidencias, aunque, en ocasiones, no sean más que de procedimiento. Si el criterio de clasificación fuera el del pragmatismo, entendiendo por ello el de los efectos o influencias de las teorías en el Derecho constitucional e internacional -partiendo del supuesto de que la razón moral en una vida civilizada fundamentada en el orden ha de acabar en norma jurídica- no su capacidad de movilización de las masas, habría que establecer dos extremos, dentro de los cuales se mueven las teorías, que son el del 'nominalismo' -abstracción, utopismo, idealismo- y el realismo. Ninguna de ellas alcanzaría el concepto puro de cada extremo, pero las diferencias entre ellas serían muy grandes. Son teorías propias de la Filosofía Moral y Política que pretenden explicar qué razones morales justifican el fenómeno político de la secesión.

Este trabajo pretende, únicamente, analizar las teorías democráticas de la secesión (también llamadas plebiscitarias, asociativas, de la libre elección, de la libertad de asociación o del consentimiento individual), las que he presentado en primer lugar, que son las que tienen más elementos próximos a la abstracción y utopismo, con poca capacidad de convicción intelectual y aplicación, a no ser que coincidan con factores propios de otras teorías como podría ser el de la injusticia. El trabajo pretende, también, mostrar una panorámica general de la doctrina ante las teorías democráticas. A partir de esta

${ }^{3}$ Michael Freeman (1999: 359-367) ofrece otra clasificación de las teorías, distinguiendo teorías liberales, teorías democráticas, teorías comunitarias, teorías realistas, teorías cosmopolitas y teoría del realismo cosmopolita. Las considera teorías de la autodeterminación nacional, es decir, basadas en el principio nacionalista, a pesar de que incluye, con poca lógica, los análisis de Beran, los cuales no siguen el criterio nacional. 
introducción, expondré, en primer lugar, algunas precisiones conceptuales y, después, la teoría plebiscitaria siguiendo a los autores principales y la crítica a tal teoría, para acabar con unas conclusiones.

\section{ALGUNAS PRECISIONES CONCEPTUALES}

Para algunos autores, siempre que se produce la separación de una parte del territorio del Estado o de sus colonias para formar otro Estado, se está en presencia de la secesión. Según esto, todas las separaciones habidas desde 1945 por consecuencia del proceso de descolonización, disolución de los últimos imperios, mutuo acuerdo entre el Estado y la parte secesionista o por reparación de la conquista injusta de un país son secesiones. Este concepto amplísimo de secesión no es sólo políticamente atractivo, sino que, fundamentalmente, y es lo que importa en este trabajo, plantea problemas teóricos y metodológicos. Por ello, otros autores utilizan un concepto mucho más restringido de secesión.

El uso polisémico del término 'secesión' no sólo se produce en el campo de la Ciencia Política o de la Filosofía Política, sino también en el Derecho Internacional. Por lo que se refiere al Derecho Internacional, los internacionalistas, que lo utilizan en su amplio sentido, abarcan con él todos los casos de creación de nuevos Estados desde la descolonización hasta la devolución, con consentimiento o sin consentimiento de los anteriores Estados. Otros, por el contrario, utilizan el término para referirse al caso de la creación de un nuevo Estado mediante la separación de parte de la población y del territorio de otro Estado sin el consentimiento de éste. El término 'secesión' también incluiría el caso de que la parte separada se sumara a otro Estado ya existente, como podría ser el caso de que Irlanda del Norte se separara de Gran Bretaña y se uniera a la República de Irlanda. No entra, en cambio, en el concepto de secesión la formación de un Estado con parte de territorio de otro Estado cuando hay consentimiento. Esto, más bien, es un caso de 'devolución' (Kohen, Marcelo G.: 2006, pp. 2-3).

En este trabajo el concepto de secesión, independientemente del sentido que le dé cada autor, se utiliza en su sentido restringido, en cuanto retirada unilateral, con la oposición del Estado, de un territorio y de una población del Estado al que pertenecen. La razón está en que la secesión lleva consigo el contenido de conflicto y enfrentamiento, que también puede darse en otros tipos de separaciones, como las guerras de independencia, pero, en este caso, no dentro de la unidad del territorio del Estado. El concepto trata de ser teórico y real a la vez. Un concepto no puede ser meramente teórico, sino que ha de tener una dimensión real, de lo contrario nos cerramos al conocimiento, en este caso, de la realidad social y de su deber ser. Las teorías plebiscitarias ofrecen una respuesta normativa o prescriptiva al problema de la creación de nuevos Estados utilizando el concepto de secesión en un sentido tan 
amplio, que incluye contenidos empíricos diferentes, que, por serlo, requieren ser descritos a través de conceptos distintos. No es lo mismo una cruenta y salvaje guerra de secesión que un acuerdo pacífico de separación. $\mathrm{Ni}$ siquiera el resultado de ambos procesos es igual en ambos casos. Por ello, no se puede llamar a las dos cosas con el mismo nombre, a no ser que lo que se quiera es crear confusión. El concepto restringido de secesión no sólo es un instrumento abstracto de análisis, sino, también, de descripción de una variada realidad empírica de las creaciones de los Estados. Permite no sólo describir mejor la realidad de la secesión, sino, también, explicarla y, sobre todo, valorarla. La teoría, incluso la teoría moral, es inseparable de la realidad. Y, aunque Sartori diga que al filósofo «se le permite ignorar los hechos y ser sólo normativo, tratar sólo de ideales» (2007:12), hay que añadir que es un permiso excesivo. Lo normativo no puede estar desvinculado de lo descriptivo. Los conceptos (poder, autoridad, consenso y, se puede añadir en este caso, secesión), dice Wolin, no son cosas reales, pero su función es dar significado a los hechos políticos reales, «ya sea con fines de análisis, crítica o justificación, o una combinación de estos fines» (Wolin , 1960: 15). El concepto, pues, de secesión, se refiere aquí a una lucha entre contrarios, es esencialmente conflictivo y tiene lugar en un Estado previamente existente. Por ello, ni las separaciones pactadas, ni las descolonizaciones, ni la descomposición de los imperios, ni la independencia de un Estado conquistado por otro son secesiones en sentido estricto.

La cuestión de la definición teórica de la secesión plantea, como es lógico, un problema metodológico en la Ciencia Política, que afecta al debate de la secesión y, también, de la autodeterminación, derechos de minorías y, especialmente, de la soberanía territorial. Según escribe Bishai, la secesión es un concepto territorial, que entra en contradicción con la soberanía territorial del Estado moderno. De entrada, reduce las perspectivas de solución de los problemas de los grupos sociales a un enfrentamiento frontal con el Estado, porque no hay más solución, según esto, que la repetición del esquema de la soberanía territorial en un nuevo Estado y ello alimenta la idea de los separatistas de que no hay más opción que la independencia. La secesión, por otra parte, es un riesgo alto para la economía y la política de un Estado; obliga a redefinir el significado y la identidad del Estado; reproduce los mismos problemas que trata de solucionar, entre ellos, el del consentimiento político y el de las nuevas minorías, y fomenta con su obsesión por el control territorial los ámbitos de exclusión entre los grupos. El concepto de secesión territorial, por más lógico que pueda parecer por su relación, más que dependencia, con el Estado territorial, apuntala, aún más, que tanto la autodeterminación como la soberanía sigan entendiéndose únicamente como conceptos territoriales. Por todo ello, la idea de conflicto, propia del concepto restringido de secesión, expresa, desde un primer momento y con mayor realismo, la naturaleza del debate sobre la secesión favoreciendo la conveniente flexibilización de otros conceptos de la teoría política (Bishai, 1998: 93-94). 
Una segunda matización se refiere al concepto de derecho que utilizan las teorías que se recogen en este trabajo, cuando hablan del derecho a la autodeterminación y a la secesión. No se usa en el sentido de un derecho especial, como podría ser el derivado de un contrato, o en el sentido de un derecho fundamental recogido en una Constitución, tal que el derecho a la vida o el derecho a la libertad de expresión, sino como un derecho general, que en muchas ocasiones se expresa como derecho moral. Expresiones como derecho de un grupo a la secesión han de entenderse como derecho general o derecho moral a la secesión (Buchanam, 1998: 230).

No obstante, el autor de este trabajo utiliza el término 'derecho' en su sentido estricto, como concepto jurídico, no como concepto moral. La expresión 'derecho moral' no deja de ser una imprecisión conceptual y, cuando por respetar la literalidad de los teóricos analizados, se utiliza el término 'derecho moral', simplemente se quiere decir 'razón moral, argumento moral o exigencia moral', aunque uno discrepe de semejante moralidad.

Una tercera matización es que el derecho de autodeterminación se usa como autodeterminación para la secesión y, cuando se utiliza únicamente el término 'derecho de secesión', éste significa, también, derecho de autodeterminación para la secesión, salvo que un autor lo utilice en otro sentido, como sería el caso de hablar de derecho de autodeterminación para la autonomía, autogobierno o federalismo. Así lo hacen algunos moderados autores de la teoría democrática.

\section{LA DEFENSA DE LA AUTODETERMINACIÓN PARA LA SECE- SIÓN EN LA TEORÍA DEMOCRÁTICA. El principio de asocia- ción política voluntaria basada en el derecho individual de libre aso- ciación.}

La exposición de las teorías democráticas o plebiscitarias se hace por autores y sigue un orden cronológico. Conviene advertir que para algunos la autodeterminación para la secesión es la única alternativa, mientras que para otros la autodeterminación, según las circunstancias y los casos, está abierta a diversas posibilidades desde la secesión hasta la autonomía. Los defensores del derecho de autodeterminación para la secesión, a pesar de que parece que lo defienden como un derecho absoluto, suelen exigir más o menos condiciones para su ejercicio. Más exacto sería decir que la teoría democrática distingue entre derecho moral a la autodeterminación, que es substancial y permanente, y ejercicio de tal derecho, que es el que está sometido a condiciones. Éstas afectan a su ejercicio, pero no anulan el derecho moral sustantivo. Las verdaderas diferencias entre los autores están en las condiciones de aplicación. Es importante tenerlo en cuenta, porque son las condiciones de aplicación las que denuncian lo infundado de la conclusión inicial. 
Harry Beran escribe en uno de sus trabajos (1998: 33) que los autores que han escrito en defensa del principio de asociación política voluntaria han sido pocos y menciona a Gilbert Murray, Robert Dahl, Thomas Pogge y, especialmente, David Gautier. No obstante, también se puede considerar a Christopher Wellman, Daniel Philpott, Copp, Glaser o el mismo Beran como integrantes de esta corriente de pensamiento. Voy a exponer a continuación el análisis de estos cinco últimos autores.

David Gautier es uno de los más radicales y, aunque defiende, en principio, como criterio la libertad total para la secesión, entendida como secesión unilateral, establece alguna limitación en el ejercicio del derecho de autodeterminación. Este autor escribe pensando en el problema de Québec y, para destacar la rotundidad de su tesis, excluye de su análisis todos aquellos casos en los que se da una relación de ilegitimidad entre el Estado dominante y la parte secesionista, ilegitimidad basada, por ejemplo, en la ocupación violenta. En estos casos, el derecho de la parte secesionista a la separación se fundamentaría en la nulidad del acto de ocupación por parte del Estado dominante y no en el derecho a la secesión en el sentido en que Gautier lo defiende. El ejemplo es el de Lituania con respecto a Rusia. La separación de Lituania es legítima, porque su ocupación por Rusia era ilegítima. Así pues, todo Estado que trata injustamente a parte de sus miembros carece de legitimidad sobre ellos y, en consecuencia, tales personas tienen plena libertad para decidir lo que les convenga.

Pero el núcleo del pensamiento de Gautier se refiere al caso de los Estados legítimos -órdenes políticos legítimos-, donde no se puede hablar de ninguna opresión ni de ningún tipo de injusticia. Trata el derecho de secesión como parte de los derechos individuales, no como derecho colectivo o derecho de grupos, y el punto de partida es la idea de interacción. Su tesis se fundamenta en el derecho débil de asociación o no asociación, según el cual toda persona tiene derecho a asociarse con quienes quiere asociarse $\mathrm{y}$, a su vez, quieran asociarse con ella. Así mismo, toda persona tiene derecho a evitar o salirse de una asociación, con cuyos miembros no quiere asociarse o no quiere seguir estando. La coordinación de este derecho con los de otras personas debe hacerse de manera que el máximo posible de personas se encuentre en su asociación deseada. Este derecho actúa en ambas direcciones, para asociarse y para separarse, por lo que es legítimo un movimiento secesionista que quiera fundar un nuevo Estado o unirse a otro existente por motivos, por ejemplo, culturales o de otro tipo. (No hay que confundir el motivo con la legitimación de la secesión, ya que ésta se fundamenta en la pura voluntad individual). Pero nadie tiene derecho a asociarse o continuar en una asociación con quienes no quieren asociarse con él, dice el autor poniendo el ejemplo del matrimonio: uno tiene el derecho a casarse con la mujer que también lo quiere, pero no si no lo desea.

Gautier pone como ejemplo el caso de Irlanda del Norte, en el que la mayoría de los católicos de Irlanda del Norte y la mayoría de los ciudadanos 
de la República de Irlanda quieren unirse, mientras la mayoría de los protestantes de Irlanda del Norte quiere continuar en el Reino Unido. Si se diera el caso de una unión entre las dos Irlandas, esto sería contrario al 'derecho débil' individual, porque, al ser mayoría los protestantes de Irlanda del Norte, serían más personas las que tendrían que estar asociados con los que no quieren. El principio, pues, exige que la aceptación sea mutua y por mayoría en ambos casos, es decir, por parte de Irlanda del Norte y la República de Irlanda. El mismo argumento lleva al autor a justificar la secesión de Québec, porque, en el caso de seguir con la actual situación, la mayoría de Québec, los francófonos, estaría obligada a estar asociada con los canadienses, es decir, con los que no quieren estar asociados.

Sin embargo, el autor advierte que su teoría no justifica, siguiendo con el ejemplo anterior, que la mayoría de los británicos invocase su 'derecho débil' para separarse de Irlanda del Norte, argumentando los costes que por causa de la violencia estuviera sufriendo Gran Bretaña. Ello supondría rechazar la defensa que un Estado debe hacer de una parte de la asociación hasta ese momento aceptada y bienvenida. Sería incumplir una parte esencial del rol para el que existe una asociación política, cuyo fundamento moral, invocando a Locke, es que no se debe mejorar a costa del empeoramiento de otro. Esto no es contradictorio con lo dicho más arriba de que nadie tiene derecho a continuar en una asociación si los demás no quieren, ya que introduce el nuevo factor del enriquecimiento a costa del otro.

Según esto, el 'derecho débil' a la autodeterminación debe combinarse con otros factores, que hacen que no se pueda interpretar de una manera absoluta, no obstante su valor universal. Así, el autor añade que si la separación beneficiase a la parte secesionista a costa del Estado matriz y cargara sobre éste los costes de la separación, entonces no se podría hablar de derecho de secesión. Esta excepción, de todos modos, no puede interpretarse en sentido extensivo. Así, la mera pérdida de ventajas derivadas de la asociación o el debilitamiento de sus respectivas economías como consecuencia de la secesión no son razones para rechazar la secesión.

En definitiva, Gautier defiende que existe un amplio derecho para los miembros de un grupo a separarse de su comunidad política (Estado), incluso en el caso de que tal comunidad haya sido plenamente legítima. Así como existe un caso moral para el divorcio sin culpa, así hay un caso moral para la secesión sin culpa (Gautier, 1994: 357-372, passim).

Según Wellman, los grupos humanos pueden tener derecho a la secesión por injusticias causadas por el Estado, pero eso no constituye un derecho de secesión basado en el derecho de autodeterminación. A partir del análisis de la naturaleza de la reivindicación del Estado de su territorio político, el autor cree estar en condiciones de concluir cuándo, cómo y qué clases de grupos secesionistas pueden tener válidas reivindicaciones para con el territorio codiciado. Esto no sería así, porque fuesen tratados injustamente, sino porque, simplemente, deciden ejercitar su primario derecho de autodetermina- 
ción política. Ahora bien, puesto que el ejercicio del derecho primario de una manera absoluta -mero consentimiento- podría tener consecuencias dañinas por la proliferación de muchos minúsculos Estados, como sería el caso de que el Estado fuese incapaz de realizar su función de protección de los derechos, el derecho de los grupos a la secesión, más bien la aplicación del derecho a la secesión, depende de que el grupo secesionista y el Estado remanente sean capaces de cumplir con las funciones propias de un Estado. Esto, lógicamente, exigiría un análisis empírico caso por caso. A este modelo de análisis el autor le llama 'híbrido', ya que combina elementos propios del método de la teoría del plebiscito basado en el derecho de asociación política y elementos propios del método teleológico basado en la necesidad del cumplimiento de las funciones propias de un Estado. Según esto, cualquier grupo que reside en un territorio tiene derecho a formar su propio Estado si, en primer lugar, constituye una mayoría en ese territorio; si, en segundo lugar, es capaz, una vez constituido en Estado, de llevar a cabo las funciones legitimadoras de un Estado, principalmente, la seguridad y la justicia; y si, en tercer lugar, no perjudica al anterior Estado para cumplir esas mismas funciones legitimadoras (Wellman, 1995: 149, 161-163, 170-171; Buchanam, 1998: 236).

Daniel Philpott nos recuerda que la historia de la autodeterminación invita al escepticismo, pero recuerda, también, que es inseparable de la democracia y, por ello, defiende que cualquier grupo de individuos dentro de un territorio definido que desee gobernarse de manera más independiente disfruta, prima facie, de la autodeterminación, entendida como acuerdo legal que concede la independencia o una autonomía más grande dentro de un Estado federal. La cuestión de la autodeterminación, de este modo, queda abierta, ya que diferentes situaciones requieren diferente soluciones. Esto hace de Philpott un autor más razonable y más prudente que maneja otras alternativas que la mera secesión en sentido estricto.

La autonomía moral individual basada en el concepto de Kant es el fundamento de la autodeterminación, que, a diferencia de otras opiniones, es interpretada en el sentido de autodeterminación democrática. La autonomía es la fuente del liberalismo y de la democracia. El derecho de autodeterminación es una exigencia de la democracia liberal. La autonomía no se entiende como la oportunidad de elección, sino como la actuación cuidadosa y reflexiva de acuerdo con la razón práctica de cada uno. La dimensión institucional de la autonomía exige que el derecho proteja la libertad negativa y la libertad positiva -de manera que ésta permita actuar deliberada y reflexivamente-, así como las instituciones políticas -de leyes y estructuras de gobierno- y la justicia distributiva.

De estas tres exigencias es la de las instituciones democráticas la que implica la autodeterminación. Ésta es única en promover la democracia para un grupo, cuyos miembros reclaman en primer lugar compartir una identidad con objetivos políticos y, en segundo lugar, buscar un gobierno separado del 
gobierno del Estado. No se trata de la única identidad de los miembros del grupo, sino de la identidad conforme a la cual quieren gobernarse.

Las razones para la autodeterminación, piensa Philpott, no se reducen a la actividad de gobierno; pueden ser otras como el deseo de extender la lengua, educar a los niños en sus costumbres, salvar la religión, superar las amenazas a la identidad y la cultura en peligro, evitar las persecuciones y el abandono económico, dejar de estar conquistados o divididos por la diplomacia internacional y otras posibles razones. Pero, aunque estas razones distintas del mero autogobierno pueden ser moralmente relevantes para la autodeterminación, ninguna es necesaria. La pretensión de participar mejor en política y de estar mejor representados en la gestión de sus propios asuntos aumenta la autonomía de sus miembros y la autonomía, ésta es la clave, está en el centro de la justificación de la autodeterminación.

Ahora bien, aunque la mayoría, en parte, aspira a la autodeterminación por su intrínseco valor, también lo hace motivada por otras pretensiones y son esas otras pretensiones las que hay que analizar, porque puede ocurrir que, a la vez que no hace falta ninguna motivación especial para la justificación del derecho de secesión, las otras pretensiones puedan de hecho quitar valor a tal derecho. Esto ocurre cuando los objetivos que acompañan al deseo de la autodeterminación levantan la perspectiva de la injusticia. En tales casos, es decir, cuando los que reivindican la autodeterminación son los esclavistas, los opresores de minorías o los ladrones, como cualquier plan que comprometa la autonomía, hay que tomar medidas que o bien impidan la injusticia a través, por ejemplo, de una autonomía federal, o bien radicalmente nieguen la autodeterminación. Así, las motivaciones injustas, y sólo ellas, pueden condicionar la autodeterminación.

El valor de la autonomía lo es para todos, tanto para los separatistas como para los miembros del anterior Estado de manera que la potenciación de la autonomía de unos no debe limitar la de los otros. Por ello, la autodeterminación sólo puede ser justificada de manera condicional. El recurso al federalismo para suavizar los ataques a la autonomía explica el carácter condicional de la autodeterminación. Los separatistas tienen únicamente derecho a aquellos poderes y prerrogativas que respetan la autonomía de los anteriores conciudadanos.

El problema que ahora se plantea es el de determinar el grupo al que corresponde la autodeterminación. Para muchos autores es una cuestión virtualmente insoluble. Para Philpott, ni la etnicidad ni ningún otro rasgo objetivo puede ser el criterio de identificación del sujeto de la autodeterminación. $\mathrm{Y}$, puesto que responder a este problema supone determinar las fronteras territoriales, no hay más alternativa, frente a la arbitrariedad, compatible con la democracia liberal que la decisión y aprobación por sus habitantes.

Como la autodeterminación no sólo crea un nuevo Estado o una región autónoma, sino, también, separa y coloca bajo un nuevo tipo de soberanía la tierra del viejo Estado, esto plantea la cuestión de si un grupo puede, además 
de reivindicar un nuevo gobierno, reivindicar la tierra. Así como Buchanam defiende que la reivindicación de la tierra ha de ser justificada como condición previa para el ejercicio del derecho de secesión, Philpott defiende que el legítimo derecho de autodeterminación lleva consigo la tierra que el nuevo gobierno ha de administrar y proteger.

Pero, aunque la autodeterminación sea un derecho general, no quiere decir que no esté sometido a ciertas reservas, como las que se derivarían de determinadas intenciones de los separatistas (establecer la esclavitud) o de previsibles consecuencias perversas. No se justificaría, según esto, una descolonización que condujera a la negación del más mínimo contenido de la democracia liberal disfrutada ya en la situación colonial, es decir, a la negación de los derechos humanos básicos, aunque sí se podría aceptar la disminución de ciertos derechos, por ejemplo, electorales o educativos, para proteger la cultura entendida como contexto de elección. En el caso de la negación total del liberalismo, salvo secesión de otro Estado despótico, no cabe la justificación de la autodeterminación. Esto hace que la autodeterminación sea algo más restringido que lo que sugiere la afirmación inicial.

A diferencia de lo que dicen los remedialistas, no hace falta demostrar que el grupo separatista sufre injusticias, por muy importantes que éstas sean moralmente hablando. El derecho de autodeterminación no necesita de ellas, porque el criterio definitivo no es la injusticia, sino la existencia del grupo que quiere la autodeterminación, sufra injusticias o no las sufra. Para Philpott, en todos los Estados hay gente discriminada, pero en pocos se puede hablar de que esas injusticias las sufren por ser integrantes de determinados grupos. La masa, la gente, no forma grupos más que cuando sus miembros se identifican como grupo que quiere desarrollar sus propios fines. Con la conciencia de grupo se adquiere estatus moral y el autogobierno, que fundamenta el derecho de autodeterminación. La injusticia puede ayudar a fortalecer la identidad y la solidaridad de un grupo e, incluso, ser un motivo para la autodeterminación, pero no crea al grupo como tal.

Sin embargo, Philpott considera que, cuando la cultura está en peligro o un grupo está amenazado de genocidio, está justificada la autodeterminación, tanto desde el punto de vista democrático como desde el punto de vista de los derechos humanos. En estos casos, la independencia puede ser el único modo de impedir tales violaciones.

En cuanto al problema de los disidentes (personas que pertenecen a un grupo, pero que no están de acuerdo con la separación) y minorías (no pertenecen al grupo) el problema está en saber qué reivindicaciones están justificadas, dado que no se trata de un grupo homogéneo. En el caso de los disidentes, el criterio a aplicar debe ser el mayoritario a través del plebiscito. Si se trata de las minorías, donde el territorio no es homogéneo, la decisión corresponde a la mayoría de habitantes del territorio, pero con la salvedad de que los derechos de la minoría, incluidos los culturales, deben ser garantizados por el nuevo gobierno. Esto quiere decir que la autonomía de la mayoría 
no debe ganarse a cuenta de los derechos de las minorías. Pero, hay otra cuestión en el caso de las minorías y es que se puede hablar de la existencia de un territorio homogéneo dentro de otro territorio heterogéneo, ya que estas minorías ocupan su propio enclave. En este caso, la lógica exige tratar a este enclave como un candidato a elegir su propio destino mediante la decisión de su propia mayoría.

Pero, más allá de los principios y de la teoría, como la aplicación de la autodeterminación suele producir malas consecuencias (guerra y refugiados, por ejemplo), Philppott se replantea la cuestión del derecho de autodeterminación desde ese punto de vista. El resultado es la moderación del derecho de acuerdo con el principio básico de la proporcionalidad y la distinción entre los tipos de autodeterminación, ya que las consecuencias de la secesión no son las mismas que las de otras formas de autodeterminación. Por ello, de manera general, se puede garantizar un derecho general a la autodeterminación de un grupo siempre que su nivel de justicia (liberalismo, principio mayoritario y respeto de las minorías) sea tan alto como el del Estado de origen. Su nivel de autonomía es variable y aumenta, hasta la secesión, de acuerdo con los agravios y amenazas sufridas y desciende hacia otras formas más suaves de autonomía, cuando la separación suponga la limitación de la autonomía de los miembros del Estado. La justicia de la autodeterminación y cualquier injusticia sufrida hay que sopesarlas con la perspectiva de la guerra o el caos. En definitiva, la secesión es el último resorte que aplicar; únicamente, cuando ninguna otra alternativa es suficiente.

La autodeterminación se justifica en la medida en que promueve la democracia, pero el éxito de la democracia depende de su estabilidad y las soluciones democráticas estables no necesitan ser siempre mayoritarias, ya que determinadas medidas que permiten el autogobierno de los grupos y la defensa de sus intereses, además de tomar parte en las decisiones del Estado entero, son formas de autodeterminación que han probado su estabilidad. De ninguna manera, concluye el autor, el reconocimiento de la autodeterminación en el sentido en que lo ha establecido produciría un desastre humanitario, ya que, en primer lugar, permite pocas secesiones y rechaza muchas reclamaciones de autonomía federal. La legalización de la autodeterminación y su prudente aplicación por los más poderosos Estados contribuiría, no a la anarquía, sino al orden y a la estabilidad. El autor sentencia que los grupos divididos no tienen futuro, pero tales grupos estarán menos divididos, si sus miembros se sienten respetados (Philpott, 1995: 352-385, passim) ${ }^{4}$.

El análisis de David Copp sobre si algún tipo de grupo dentro de un Estado tiene derecho a la secesión se plantea en el contexto más amplio de la división política. La cuestión a estudiar es qué grupos y en qué territorios tie-

\footnotetext{
${ }^{4}$ El argumento de la autonomía como fundamento del derecho de secesión aparece, también, en Philpott (1998: 82-83.100).
} 
nen el derecho a constituirse en Estados, es decir, qué grupos tienen el derecho de autodeterminación. La tesis de Copp es que las sociedades con un territorio (sociedades territoriales) y un deseo permanente por el autogobierno tienen el derecho para constituirse en Estados. Por el contrario, las naciones, en un mundo de sociedades pluralistas, carecen de tal derecho. Lo mismo les ocurre a ciertos grupos culturalmente homogéneos.

Aunque Copp defiende que el derecho de autodeterminación consiste en el derecho de un grupo a adquirir la condición de Estado o, si ya lo es, en el derecho a continuar siéndolo, el fundamento de tal derecho está en los derechos democráticos de sus miembros; ahora bien, hace falta que los individuos formen un grupo social determinado, el de una sociedad territorial y política. No se trata de un derecho absoluto, ya que puede haber circunstancias en las que no se pueda ejercer tal derecho, como podrían ser aquéllas en las que están en juego la paz y la seguridad internacionales. En estos casos tiene que haber una compensación, que podría ser la de un autogobierno limitado dentro del Estado.

El sujeto de este mal llamado derecho moral a la autodeterminación es el Estado, pero también lo puede tener algún grupo interno del Estado, ya que el derecho del Estado sobre su territorio no tiene más contenido que el de imponer en él su ordenamiento jurídico, ejercer un efectivo control e impedir interferencias ajenas sobre su acción de gobierno, pero no incluye el rechazo del derecho de secesión. Si, por tanto, un grupo o una entidad dentro del Estado tiene el derecho de secesión, éste incluye un derecho sobre su territorio de la misma naturaleza que el del Estado con la correspondiente libertad de plantear un plebiscito para crear un Estado en su territorio y el poder de adquirir el derecho a gobernar en su territorio. Y este derecho a la secesión no está ligado a la injusticia.

Los elementos definitorios de estos grupos, que pueden separarse legítimamente del Estado, son el de 'sociedad', 'territorio' y 'política', cuyo fundamento último es la democracia. El autor no desarrolla ninguna teoría de la democracia. Simplemente utiliza lo que, según él, defienden los demócratas como idea principal y que considera suficiente fundamento de su teoría. Lo esencial de la democracia, de donde nacen todos los demás poderes, es el gobierno conforme con una constitución que establece que son los ciudadanos los que de manera igual disponen de la autoridad sobre las decisiones políticas. Por tanto, el principio básico de la democracia es la igualdad de todos los ciudadanos, que, a su vez, exige la igual autoridad de todos ellos sobre las decisiones políticas. Y esto ha de aplicarse lo mismo al Estado que a cualquier otro grupo interno al Estado, que ocupara un territorio o tuviera derecho a ocuparlo y en el que podría construir un Estado, si hubiese un deseo estable por lograrlo.

Por sociedad se entiende un gran grupo, comparable en tamaño al de la población de un Estado, de historia multigeneracional y con capacidad para existir varias generaciones (la creación de instituciones que conviertan una 
población en un Estado puede durar varias generaciones y, más, si se trata de un Estado democrático), caracterizado por una red de relaciones sociales (incluida la del compañerismo) y por normas de cooperación y coordinación, fundamentales para la construcción institucional del Estado. El grupo abarca, con un criterio ampliamente comprehensivo, a toda la población de residentes permanentes de un territorio relevante con la excepción de los recién llegados, que todavía no están integrados en la red de relaciones sociales, porque, por ejemplo, no tienen todavía amigos o conocidos en el grupo, y con la exclusión de los emigrantes.

Por 'política' se entiende la voluntad estable -no simplemente esporádica- y generalizada del grupo de querer formar un Estado, bien sean razones culturales o tradicionales u objetivos políticos los que expliquen esta permanencia general. En caso contrario, el Estado estaría legitimado para impedir la secesión de tal sociedad.

En lo que se refiere al territorio, éste ha de ser considerado una región de tierra o una suma de regiones de tierra, donde pueda desarrollarse cualquier tipo de relación social significativa y donde sea factible construir un Estado. El territorio de una sociedad es aquél en el que virtualmente todos los miembros de la sociedad residen permanentemente y virtualmente todos los residentes permanentes del territorio son miembros de la sociedad. Las dudas pueden surgir en torno al inmigrante, pero, en cualquier caso, cualquier permanente residente del territorio debe ser tenido como miembro de la sociedad durante el período de su permanente residencia. Su razón estriba en que si una sociedad tiene el derecho de autodeterminación, democráticamente hablando, cualquier decisión sobre la soberanía, es decir, sobre la conversión de una sociedad en Estado, debe ser decidida por todos los miembros de la sociedad. No es éste el caso de los residentes temporales. La sociedad territorial puede tener ya su territorio o el derecho a ocuparlo por razones históricas u otras consideraciones a pesar de que no lo ocupe en la actualidad. Pero la sociedad, que no ocupa un territorio o carece de un especial derecho moral a ocuparlo, no tiene el derecho de autodeterminación al carecer del poder para constituirse en Estado. Ahora bien, una sociedad territorial y política, según criterios democráticos, tiene el derecho a que no se le impida realizar un plebiscito para formar un Estado y, supuesto el apoyo mayoritario a favor de la creación del Estado, tiene derecho a que ningún otro Estado interfiera en su creación.

Copp no se limita a defender qué grupos tienen derecho a la secesión, sino, también, a rechazar expresamente a aquellos que, en su opinión, no tienen tal derecho. En primer lugar están los grupos culturales, lo que algunos autores llaman 'grupos abarcantes' ${ }^{5}$. Tales grupos tienen un carácter común y una cultura común que es dominante abarcando muchos, variados e impor-

${ }^{5}$ Ver Avishai Margalit y Joseph Raz (1990: 439-61). 
tantes aspectos de la vida, de manera que los miembros de tales grupos están marcados por el carácter de la cultura del grupo. Estos grupos afincados en un territorio, por ejemplo, los francófonos en Québec, con una identidad propia basada en su cultura, serían el sujeto de la autodeterminación. El criterio excluye del derecho de autodeterminación a todos los habitantes del territorio que no formen parte de tal grupo cultural. Únicamente contaría la voluntad de los grupos que forman la substancial mayoría 'abarcante'.

La razón del rechazo de este criterio está en que es contrario a los principios democráticos e igualitarios, además de utilizar un impreciso concepto de 'cultura' y un especialmente resbaladizo criterio de 'identidad'. El argumento cultural insiste en la importancia del Estado para el bienestar de los miembros del grupo cultural 'abarcante', pero olvida que también el bienestar de los demás quedará afectado por la creación de un nuevo Estado. Por tanto, el mismo argumento sirve para defender que el derecho de autodeterminación pertenece a toda la población del territorio.

De la misma manera, el argumento cultural abarcante habría que reconocerlo a las poblaciones de las muchas sociedades plurales existentes, donde hay diversos grupos abarcantes y, en muchos casos, el grupo no abarcante es la mayoría substancial en cualquier parte del territorio. Si se dice que el bienestar de los pertenecientes a los grupos abarcantes depende de la prosperidad del grupo, lo mismo cabe decir de los miembros de sociedades pluralistas respecto a la prosperidad de su sociedad. Por otra parte, argumentar con que la identidad, como parte esencial de la prosperidad de cada miembro, depende del grupo abarcante más que de toda la sociedad, olvida que la naturaleza multicultural de las sociedades plurales puede ser mucho más importante para la persona que la cultura de su propio grupo. Además, no cabe deducir de la conveniencia de que un grupo tenga su propio Estado que tal grupo tiene derecho a tenerlo.

Y, en segundo lugar, están las naciones, sobre las que Copp piensa que tienen similares problemas que los grupos culturales. Una nación es casi siempre una parte propiamente dicha de una sociedad en un territorio y sería antidemocrático que dispusiera del derecho en lugar de toda la sociedad. Además, una nación no tiene que estar necesariamente organizada en Estado, ni un Estado tiene que ser necesariamente la forma política de una nación.

La nación, un grupo que existe desde hace varias generaciones, ha de incluir, según Copp, otros elementos. En primer lugar, que el grupo tenga una historia y una tradición con las que sus miembros se identifiquen sentimentalmente (orgullo, vergüienza, resentimiento) y sean a la vez aceptados como miembros por otros que se identifican de la misma manera. En segundo lugar, que exista entre los miembros de la nación la aspiración o el deseo, entendido en un amplio sentido, estable y generalizado de que el grupo se convierta en Estado. Ésta es la manera de entender a las naciones como grupos políticos. Y en tercer lugar, la nación ha de tener un territorio en el que el Estado pueda formarse de manera factible para los miembros, exactamen- 
te, de la nación o, al menos, la mayoría de sus miembros, independientemente de que el territorio esté dividido por una frontera actual.

Pues bien, lo común es pensar que las naciones tienen el derecho de autodeterminación, pero Copp advierte de que la nación no es ni necesaria ni suficiente para que un grupo tenga el derecho de autodeterminación. Una sociedad multinacional puede tener el derecho de autodeterminación sin tener un carácter nacional y sin tener una historia y unas tradiciones comunes. Y en lo que se refiere a que el carácter nacional sea una condición suficiente, conviene aclarar que los miembros de una nación pueden estar mezclados en el mismo territorio con los no miembros a semejanza de lo que ocurre en Québec. Aplicando los criterios nacionales, los miembros de la sociedad, residentes permanentes del territorio de la nación, podrían ser excluidos de la nación por no reunir alguna de las condiciones del carácter nacional. Según esto, sería antidemocrático conceder el derecho de autodeterminación a la nación y no a la sociedad dentro de la que está la nación, ya que determinados miembros de la sociedad, los ajenos a la nación en cuestión, se verían privados del voto. Las razones democráticas parece que avalan, también, la idea de que el derecho de autodeterminación pertenece propiamente a toda la sociedad de un territorio más bien que a una nación en los casos en que la nación no sea toda la sociedad. Los criterios democráticos sugieren 'que si el derecho pertenece a algún grupo, éste es el que forma una sociedad completa', es decir, la sociedad territorial y política. Si éste fuera el caso de Québec, añade el autor, los derechos de Canadá no incluyen el derecho de mantener su unidad impidiendo a Québec su secesión. El derecho de gobierno no da derecho contra los ciudadanos del Estado para que éstos no interfieran, sino todo lo contrario, ya que la democracia exige que las instituciones del Estado se dispongan de tal manera que todos los ciudadanos por igual puedan 'interferir'. Por ello, todos los quebequeses, independientemente de su cultura y lengua, como miembros de la sociedad, tendrían autoridad sobre el derecho de secesión. La conclusión es que, si un grupo es una sociedad territorial y política, tiene el derecho de autodeterminación fundamentado en los derechos democráticos de sus miembros. Copp no usa el término de sociedad 'distinta', aunque podría usarlo, siempre que se interpretara lo distinto no como un conjunto de condiciones prepolíticas (v. g. culturales), sino como condiciones, en primer lugar, política, voluntad de los integrantes del grupo social de formar otro Estado, y, en segundo lugar, territorial, territorio propio con capacidad para vivir en grupo y formar un $\operatorname{Estado}^{6}$ (Copp, 1997: 277-300, passim).

\footnotetext{
${ }^{6} \mathrm{El}$ autor confiesa en el artículo citado algo difícil de entender en un análisis con pretensiones científicas, al afirmar que sus argumentos son incompletos debido, en parte, a que los conocimientos básicos de democracia no los tiene muy claros. Como crítica se puede decir que es contrario a cualquier planteamiento científico establecer un marco teórico de análisis de un problema que el investigador dice desconocer, al menos, en parte, como es, en este caso, la democracia. Puede ser una confesión honesta, pero no anula el problema académico que ella supone.
} 
Harry Beran justifica el derecho de autodeterminación y secesión fundamentándolo exclusivamente en el derecho individual de libre asociación. Su teoría se formula como derecho moral a la autodeterminación política y a la secesión. Según esto, no les hace falta a los individuos, por tanto, ningún agravio ni situación de injusticia para justificar el derecho a formar comunidades territoriales en la tierra que ellos tienen o adquieren legítimamente. Tampoco necesitan creer que participan de otras características que el mero deseo de formar otro Estado, ni necesitan tener una identidad étnica o cultural común. Los individuos de cualquier grupo, por heterogéneo que sea, tienen el derecho de secesión. Basta tener la mayoría en cualquier parte del territorio del Estado. Es la 'teoría del plebiscito', que exige el asentimiento actual de los individuos. Aunque Beran reconoce la distancia de su pensamiento con la realidad, no duda en afirmar que la separación pacífica entre Chequia y Eslovaquia y la supuesta renuncia de Canadá a la fuerza ante el caso de Québec muestran el carácter no utópico de su teoría.

Beran resume su teoría democrática de la autodeterminación personal en los siguientes puntos: a) toda persona adulta normal tiene el derecho de autodeterminación personal y, por consiguiente, el de libertad de asociación con quienes también lo quieran; b) las comunidades territoriales (Estado, entendido en último término como pueblo o conjunto de individuos o parte de la población, nación y comunidades de grupos territoriales y no territoriales, en definitiva, grupo social en un común hábitat, compuesto de numerosas familias, que es capaz de perpetuarse a través del tiempo en cuanto entidad distinta, y cuyos miembros tienen entre sí relaciones directas y variadas, intereses comunes, sentido de pertenencia al grupo y conciencia de ser un grupo distinto) que tienen legítimamente su territorio, tienen el derecho de continuar ocupando su territorio; c) el derecho de autodeterminación política de un grupo requiere que éste sea no sólo una comunidad territorial, sino que sea, también, viable política y económicamente en cuanto entidad independiente; d) el derecho de autodeterminación de una comunidad territorial compuesta de comunidades territoriales más pequeñas se deriva del derecho de éstas en razón del principio de libre asociación; por ello, en caso de conflicto de fronteras entre una comunidad pequeña y otra más grande, prevalece siempre el derecho de la más pequeña; e) el derecho de autodeterminación política de una comunidad se ejercerá de acuerdo con el principio de mayoría, normalmente en referéndum, pero, si la cuestión estuviese clara, no haría falta el recurso al referéndum; f) el derecho de autodeterminación incluye el derecho de secesión acordada, por lo que su ejercicio está sujeto a la justa división de los activos y deudas del anterior Estado. En esencia, la secesión debe ser permitida, si la desea un grupo territorialmente concentrado dentro de un Estado y si es moralmente y prácticamente posible.

Beran advierte que los costes, las alteraciones e inconvenientes de la secesión son tan considerables, que tiene que haber fuertes razones para hacerla, razones que no eliminan la negociación subsiguiente. Así mismo, 
considera que su teoría, para ser más convincente, requiere un contexto teórico formado por un acuerdo entre todas las comunidades del mundo sobre los principios morales directamente relevantes para la autodeterminación, una justicia distributiva internacional, una estratificación de niveles de gobierno (mundial, continental, estatal, provincial y local) siguiendo el criterio de Dahl de las cajas chinas como modelo de organización y la aceptación del criterio de unas fronteras legítimas en lugar de las mejores fronteras.

A pesar de la rotundidad de su teoría, Beran admite en la práctica excepciones a ésta como sería el caso de que una pequeña parte del territorio, que quiere separarse, fuera fundamental para evitar una invasión del Estado anterior y los separatistas se negaran a un acuerdo conjunto sobre el territorio. En este caso, el derecho del Estado anterior a la paz puede anular el derecho de autodeterminación. El Estado también podría oponerse a la secesión en el supuesto de que la parte secesionista se quedara con todas las fuentes de riqueza y no quisiera compartirlas con el anterior Estado.

El resultado de la aplicación de la teoría democrática, dice Beran, sería el aumento del número de Estados y de las naciones-estados, el desarrollo creciente de los lazos económicos y políticos entre Estados así como el fortalecimiento de mecanismos de decisión global, la integración creciente de los ejércitos que haría difícil su uso por parte de un Estado contra otro y, por fin, un uso mayor de las Cortes internacionales, en lugar de la guerra para resolver disputas.

Beran responde a la crítica de que la aplicación de su teoría aumentaría tanto el número de Estados que haría imposible el gobierno de la humanidad diciendo que es verdad que aumentaría considerablemente, pero no tanto como para caer en la ingobernabilidad, ya que la inviabilidad de determinados pretendientes no permitiría su creación y, por otra parte, comunidades territoriales viables preferirían usar la autodeterminación para un mayor control de sus asuntos internos o un mayor papel en el orden internacional, pero dentro de una comunidad política mayor, ya que esto les sería ventajoso.

El problema que aquí se plantea es el de la condición de comunidad 'distinta' para que pueda tener lugar el derecho de autodeterminación. Beran defiende que si se acepta su teoría, que recoge las características de tales grupos sociales (comunidad territorial, política y económicamente viable), la comprobación de tal realidad es una cuestión meramente empírica y no sería difícil determinar mirando pueblos y ciudades pequeñas si son comunidades distintas. Esto responde al criterio del autor de que una teoría convincente de la secesión legítima sólo puede serlo en cuanto parte de una teoría normativa comprensiva de las fronteras (Beran, 1998: 32-59, passim).

El análisis de D. J. Glaser podría estar entre los defensores del derecho de secesión basado, como hemos visto en otros autores, en el principio de libertad de asociación, o entre los contrarios a la secesión, ya que, en su opinión, hay buenas razones para no usar tal derecho, sin que esto quiera decir 
que el derecho desaparezca. Glaser se define a sí mismo como teórico defensor del derecho primario a la secesión, por tanto, no remedial, a partir de las premisas del liberalismo igualitario o socialismo democrático. Su defensa del derecho, a la vez que su oposición a ejercitarlo y a que no sea reconocido, parece un claro inicio de la falta de sistematicidad en el análisis que realiza y, especialmente, una muestra de servidumbre dogmática.

Glaser argumenta que la forma política más coherente con el derecho individual a vivir (su propio autogobierno) como seres autogobernantes es la asociación voluntaria. La democracia (la asociación democrática), así, tiene por fundamento el consenso popular y la pertenencia voluntaria, es decir, consiste en que la gente, al margen de sus diferencias en otras cuestiones, esté conforme en vivir juntos y en observar unas mismas leyes. Pero el hecho de que la mayoría de los Estados no se base en el consentimiento popular no sólo lleva consigo que mucha gente pertenezca a Estados de los que no quiere ser parte, sino que debilita tanto la legitimidad moral como la legitimidad empírica del Estado. En estos casos poca gente se siente controlando sus destinos y más gente se siente alienada con sus gobiernos. Sería bueno, en lo que se refiere a las fronteras de los Estados, supuesto que no hay nada en este sentido predeterminado o natural, que se decidiesen, coeteris paribus, democráticamente. Esto supone defender la secesión, pero no defender que la secesión sea algo bueno o que la multiplicación de Estados sea positiva. De todos modos, el derecho a la secesión no es absoluto, sino limitado. En este sentido, Glaser expone una serie de observaciones, tanto conceptuales como prácticas, que suponen, en buena medida, un salto del dogma a la realidad.

En primer lugar, está la definición del territorio, es decir, la unidad del territorio objeto de la secesión, y la determinación de los votantes a participar en el referéndum. En segundo lugar, está la vulnerabilidad de las minorías antisecesionistas en el nuevo Estado y, en tercer lugar, la posible pérdida de valores democráticos en el nuevo Estado, si, por ejemplo, la secesión supone dejar un Estado democrático para fundar otro no democrático. Por otra parte, están las cuestiones relativas al reparto de los bienes generados en común y de los recursos naturales explotados en común, cuando ocurre que tales bienes están en el territorio secesionista.

Nada de esto anula el derecho de secesión, pero obliga a sopesar otras razones morales y a tener en cuenta otros derechos, de manera que toda secesión debería cumplir cuatro criterios fundamentales para ser legítima. En primer lugar, debe ser apoyada por una mayoría estable de residentes en el territorio secesionista, siempre y cuando la población del territorio no hubiera sido creada artificialmente en un pasado reciente. Sólo los adultos residentes podrían participar en el plebiscito de secesión. En segundo lugar, la delimitación del territorio debe hacerse de manera que incluya al máximo posible de secesionistas y reduzca al mínimo posible el número de antisecesionistas. En tercer lugar, han de respetarse los derechos básicos de todos los ciudadanos, incluidos los miembros de las minorías antisecesionistas. Y, en cuarto 
lugar, la distribución de los activos y responsabilidades entre el anterior y el nuevo Estado, y, en el supuesto de que el territorio secesionista suponga llevar la mayor parte de los bienes comunes, la parte secesionista tendrá que o bien renunciar a parte de su demanda territorial o bien pagar una compensación.

En cuanto a si la democracia en el Estado disidente debe ser una condición para la secesión (ésta es la opinión de Nielsen, a quien cita el autor ${ }^{7}$ ), Glaser considera que sólo los Estados respetuosos con los derechos humanos podrían imponer tal condición. En el caso de Estados antidemocráticos, no; bastante es, viene a decir, lo que gana la democracia con la secesión. Por el contrario, podrían imponerla aquellos Estados que temiesen que el Estado secesionista se iba a comportar mucho peor que el Estado existente.

A pesar de todas estas precisiones, el derecho a la secesión sigue existiendo, pero el problema para Glaser ahora es el de si el derecho de secesión debe ejercerse o no, y si hay que animar al que lo tenga a ejercitarlo. Es ahora cuando aparece su vertiente antisecesionista como consecuencia del análisis que hace de los argumentos que habitualmente suelen utilizarse a favor de la secesión. El autor los rechaza o los pone seriamente en duda. El rechazo es evidente, no podría ser de otra forma, cuando se refiere al argumento de que la secesión reduciría el conflicto creado por los secesionistas o que la secesión promueve la libertad de asociación. Y, en relación con otros argumentos, no se niega que en algún caso no puedan aconsejar la secesión, pero con frecuencia y normalmente hablando tales argumentos son insuficientes. En concreto son los argumentos de la descentralización, valorada positivamente por la Ciencia Política durante mucho tiempo, pero, también, criticada por sus efectos de parroquialismo y amenaza a la libertad individual; el de la lengua común, útil para una democracia, pero no necesaria como lo probarían los casos de Canadá, Bélgica y Suiza (aunque el autor parece olvidar los problemas separatistas que acompañan a los dos primeros); el de que la secesión sirve para centrar la política sobre la justicia distributiva y la democracia dentro de los grupos y no sobre cuestiones étnicas, que olvida el uso por parte de los nacionalistas de las cuestiones étnicas para desviar la atención de los problemas de clase y problemas democráticos; el argumento de que la secesión podría facilitar la creación de un Estado de bienestar entre connacionales deja de lado que el nacionalismo podría usarla para contrarrestar políticas redistributivas o de clase; además, las posibles ventajas de un Estado propio para los grupos explotados han de ser sopesadas con las incertidumbres de su realización, con las pérdidas económicas para ambas partes, fruto de la secesión, y con el posible empeoramiento de la situación de los grupos subordinados del Estado anterior; y, aunque el argumento de la secesión como instrumento de supervivencia cultural es valioso y defendible,

${ }^{7}$ Ver Nielsen, K (1993: 29-43) y (1998: 103-133). 
más lo es que la opresión de las minorías culturales aumenta en Estados culturalmente homogéneos que en multiculturales. El balance de todos estos argumentos pro y contra de la secesión, concluye el autor, ha de hacerse caso por caso, como es lógico, una vez que se pasa del campo de las creencias a la realidad social y política. No obstante, a todo lo dicho se añade un último argumento para dejar de lado la secesión, que es el de la prudencia, que llama a la búsqueda de alternativas en los casos no decisivos y donde las campañas secesionistas puedan probablemente desatar la división y el conflicto. Dado que algunos de los valores que se conseguirán con la secesión se pueden realizar con otros procedimientos, como una combinación de descentralización y centralización, la secesión podría convertirse en un peligro para lograrlos.

Los puntos de vista teórico y práctico de la secesión permiten a Glaser plantearse lo que se podría recomendar a los dirigentes de un Estado ante las presiones secesionistas. Dejando de lado ingenuas recomendaciones y pensando en los secesionistas recalcitrantes, lo correcto sería que los grupos dispusieran del derecho democrático a la secesión, pero con algunas condiciones. Éstas serían las ya conocidas: el apoyo mayoritario, el mínimo de oposición a la secesión en la parte secesionista, la negociación de la distribución de los recursos y obligaciones financieras, y el compromiso de respeto a los derechos humanos. En los casos en que un movimiento secesionista no cumpliese las condiciones, el Estado podría hacer uso de una 'fuerza moderada', entendiendo por tal la que haga falta para el cumplimiento de las leyes, realización de las funciones del Estado, prohibición de organizaciones armadas, confiscación de armas y recursos, y la encarcelación de secesionistas que realicen o planifiquen actos de resistencia armada.

Ahora bien, Glaser se muestra cauteloso y un tanto reticente a que el Estado emplee más fuerza contra los grupos secesionistas, aunque en ciertos casos le parece bien. Hay que evitar, por supuesto, aquella violencia que suponga una seria violación de derechos humanos, ya que ni siquiera las posibles futuras violaciones de los derechos justifican la violación 'ilimitada' (en realidad no justifican ningún tipo de violación) de los derechos humanos en el presente. Pero, el Estado podría aumentar la violencia contra los secesionistas en el caso de que las condiciones que no se cumplieran fueran el apoyo mayoritario a la secesión y la exclusión de áreas con mayorías locales antisecesionistas, en cuyo caso, sería legítimo el uso de tropas para complementar a la policía. Si, además, hay serias razones para pensar que los secesionistas cometerían violaciones de los derechos tales como el genocidio, se justificaría que el Estado utilizara in extremis la fuerza militar (habla, incluso, del uso de armas pesadas) para parar la secesión. Sin embargo, la supresión de la secesión por la fuerza ante el temor de violación de los derechos sobre la base de que muchas veces no se respetan las promesas de los secesionistas no le parece razonable, cuando la secesión está apoyada por la mayoría de la población. La razón es el alto coste moral que supondría ir contra la mayoría de la población, sumado al riesgo de que se utilice una 
fuerza no justificada. Así, en las últimas recomendaciones a los Estados insiste por dos veces en que bloquear la secesión con el uso limitado de la fuerza es legítimo, pero no lo es utilizar una fuerza 'inaceptable', concepto que únicamente se entiende como violación de los derechos fundamentales. Con ello el autor sugiere que una fuerza total para acabar con la secesión, de hecho, llevaría consigo una violación de los derechos humanos o, al menos, un altísimo riesgo de que ello ocurriese.

En definitiva, los consejos que Glaser propone a los Estados van en este orden: atender las demandas secesionistas legítimas, salvo la secesión; permitir las secesiones que cumplan las cuatro condiciones anteriormente señaladas, es decir, reconocer un derecho a la secesión condicional; bloquear la secesión, cuando no se cumplan tales condiciones, mediante el uso limitado de la fuerza, si es preciso, y, en el caso de que la anulación de la supresión requiriese el uso de una fuerza 'inaceptable', habría que moderar algunas de las exigencias de la secesión y conducir lo relativo a derechos humanos, democracia y justicia distributiva a un nivel interestatal para garantizar su realización. Este modo de entender la secesión, cree el autor, sería una forma más propicia para garantizar una paz justa, desanimar a usar la secesión, que debería ser el último recurso, y evitar la supresión de los movimientos secesionistas por la fuerza, aunque no hay garantías de que se escuchen semejantes propuestas en el ámbito internacional, Derecho Internacional y Convenciones, siempre mucho más respetuosos con la integridad territorial de los Estados.

Con respecto a la cuestión de si un reconocimiento más radical del derecho a la secesión podría dar lugar a una interminable división de los Estados, guerras civiles y anarquía internacional, el autor piensa que efectivamente las demandas secesionistas acarrean conflictos y su constatación histórica es una prueba moral contra la secesión. Pero, lo que importa es encontrar un lenguaje que desanime para la secesión a la vez que reconoce el derecho a ella. En términos de pareja, el autor defiende que su trabajo recoge la intuición de que el divorcio no es una buena cosa en una relación no abusiva, pero nadie debería ser forzado a permanecer casado ni siquiera con un compañero no abusivo (Glaser, 2003: 371-383).

\section{LA CRÍTICA A LAS TEORÍAS ASOCIATIVAS}

La crítica que desarrollo a continuación en relación con las teorías asociativas o plebiscitarias tiene en cuenta tres cuestiones distintas, pero interdependientes entre sí: el marco teórico y método de análisis, la contribución al desarrollo del Derecho Internacional, y la relación entre Filosofía Política y Derecho Internacional. En esta parte sólo me refiero a la autodeterminación para la secesión y no para otras alternativas, en cuyo caso las teorías democráticas siguen siendo deficientes, aunque propongan objetivos legítimos. 


\section{El marco teórico y el método}

Todos los autores defensores de las teorías asociativas tienen a la democracia y el liberalismo por fundamento de su argumentación a favor de la autodeterminación y secesión unilateral. La utilización de algún otro término, socialismo liberal o liberalismo, no afecta a esta afirmación inicial. En este sentido, no hay diferencias entre los autores analizados. Las diferencias surgen en torno a las condiciones de su aplicación, donde se observa una notable discrepancia hasta el punto de que la permisividad y la generosidad de algunos teóricos con la secesión se convierte en un rechazo en la práctica por parte de otros. Pero la cuestión básica para analizar no la constituye el conjunto de salvedades que introducen los autores, sino la fundamentación básica inicial común a todos ellos, a pesar de que la racionalidad y la razonabilidad no están en la conclusión del derecho general a la secesión, sino en las condiciones para el ejercicio del derecho, especialmente, en los casos de Copp, Beran, Philpott y Glaser.

La democracia, entiéndase democracia liberal, tiene para estas teorías el valor de norma universal que no sólo ha de aplicarse para legitimar al gobierno de un Estado o a los representantes del pueblo de ciudadanos, sino, también, a todas las cuestiones políticas y, entre ellas, la determinación de las fronteras del Estado. Nada ha de escapar a la decisión democrática de los individuos. El problema es el de si la democracia liberal, así entendida, constituye un marco teórico suficiente de análisis para establecer de manera determinante los criterios morales normativos de los territorios de los Estados. Detrás de esto está el supuesto de que toda teoría debe brindar un modelo de descripción, explicación y valoración del objeto de análisis, además de integrar los elementos tanto teóricos como prácticos.

Como ya se ha dicho, en nombre del liberalismo se defienden dos teorías sobre la secesión. La primera dice que ningún grupo está legitimado para ejercer la secesión en un Estado justo, es decir, en un Estado que cumpla sus funciones y obligaciones. La segunda establece que la voluntad individual es el criterio determinante político y, por consiguiente, la voluntad de la mayoría, sin más, de cada territorio es el criterio decisivo en la delimitación de las fronteras de los Estados. Esto es lo que defienden las teorías democráticas o teorías de la elección. En el fondo, tales teorías son teorías nacionalistas liberadas del elemento nacional, es decir, liberadas de la necesidad de explicar el porqué del peso que la etnicidad y los rasgos culturales tienen en la argumentación a favor de la secesión. Y, puesto que la pretensión de basar la secesión en los principios de autonomía y democracia parece hacer más fácil su entronque con otras características institucionales de la democracia liberal, basados, también, en los mismos principios, estas teorías parecen dar, de entrada, un toque democrático-liberal al tema de la secesión. Tales principios, ya se sabe, son los del consentimiento, autonomía individual, libertad de asociación, autodeterminación política o democracia. Esto es un error, 
porque al prescindir del elemento nacional de las teorías nacionalistas se multiplica el número de grupos potenciales para la secesión, dejándolos a merced de la mayoría de las objeciones que se hacen a las teorías nacionalistas. Si se tiene en cuenta que los movimientos secesionistas del siglo XX han implicado a minorías étnico-culturales y que la mayoría de las teorías de la elección creen que los casos de conflictos étnicos encuentran soluciones en la aplicación de los derechos de las minorías y el federalismo y, únicamente, como último recurso, en la secesión, resulta que no tiene sentido tratar a las minorías étnicas según sus peculiaridades en cuanto grupos y, cuando piden la secesión, tratarlos, no como grupos diferentes, sino como conjuntos de individuos (Norman, 1998: 37-39).

Para Miller, si se cumple el principio de la voluntad individual se cae en la anarquía y si se cumplen las condiciones de su aplicación se acaba en la arbitrariedad. Además, es ilusorio pensar que el resultado de aplicar el principio de mayorías va a dejar a cada individuo en el Estado que desea. Habrá vencedores y perdedores, y para valorar los nuevos Estados habrá que tener en cuenta ganancias y pérdidas y no sólo 'contar cabezas' (Miller, 1997: 139-140). Los datos históricos prueban, más bien, que las consecuencias de las secesiones son negativas, ya que raramente la secesión pone fin a las luchas o al terrorismo. Además, la secesión es económicamente perjudicial para ambas partes y los nuevos Estados, consecuencia de la separación, son generalmente menos democráticos que los Estados originales (Spencer, 1998: 23).

Estas críticas válidas dejan de lado aspectos básicos que afectan directamente al marco teórico de análisis y destacan la incapacidad o insuficiencia de la teoría democrática para explicar la secesión. Entre los elementos que no son tenidos en cuenta y que son imprescindibles para una teoría científica cabe destacar la falta de explicación y de justificación de que algunos grupos sean expulsados de su Estado contra su voluntad y contra la voluntad de la mayoría del Estado; el porqué de la exclusión de otras alternativas a la secesión y a la unión; la arbitrariedad a que da lugar la falta de criterios sistemáticos; la falsa convicción de que la democracia sea, por definición, justa y suficiente criterio de legitimidad, cuando en realidad puede ser contraria a elementales derechos individuales (acaparamiento de la riqueza, historia de opresiones, negación de los derechos a los integrantes de minorías) y, por ello, ser contraria a principios básicos liberales; la falta de correspondencia entre el concepto de autodeterminación individual y la capacidad operativa real de cooperación de la persona; la falsedad de que la autodeterminación de un territorio es algo que no tiene nada que ver con los vecinos ni con la comunidad internacional; la falsedad empírica y la ficción que supone afirmar que la base para la justificación de la autoridad del Estado sea la intrínseca libertad de los individuos para crear una asociación política, cuando las deudas, como los beneficios, con el Estado empiezan con el nacimiento y continúan con la vida dentro del Estado, dependiendo de lo que se recibe del Estado, es decir, de los derechos reconocidos; la creencia de que la mera 
mejora de las condiciones económicas pueda justificar la secesión o que sea parte de una teoría liberal de la justicia defender que un grupo pueda dejar una asociación política, cuando no le resulta ventajosa, invocando la 'mutua ventaja'; la dificultad, si no imposibilidad, de establecer criterios que determinen qué individuos pertenecen al grupo, que, supuestamente tiene el derecho de secesión, cuestión que no se arregla por muchos referendos que se hagan; el supuesto falso de que toda la gente está claramente dividida en grupos en cuestiones de identidad y territorio, cuando tiene, en realidad, pluralidad de identidades; la disfuncionalidad del referéndum, no sólo porque la forma de preguntar determina ampliamente la respuesta, sino porque se trata de un instrumento burdo para la complejidad de las realidades identitarias, con lo que no se garantiza a todos la libertad de elección política ${ }^{8}$; la imposibilidad de que las técnicas plebiscitarias solucionen el problema de las minorías dispersas o integradas, de manera que los intereses de determinada gente no pueden ser tratados territorialmente; el equivocado supuesto teórico de pensar que el Estado es la única forma de organización política, que lleva al error de asumir que el derecho a determinar el estatus político debe significar el derecho a crear nuevas fronteras políticas, cuando cabe pensar en sociedades políticas no territoriales que ofrezcan la pertenencia al grupo más bien que a la ciudadanía del Estado; y, por último, la contradicción entre la defensa de la secesión como derecho individual que fundamenta una teoría normativa de la secesión y su rechazo por razones o limitaciones prácticas (Dowding, 1998: 76-79; Bishai, 1998: 100-102; Caney, 1998: 153-157).

${ }^{8}$ En este sentido hay que tener en cuenta el análisis de Olofsgard sobre los incentivos políticos en una región que amenaza con la separación, en el supuesto de que la decisión secesionista se tome en referéndum. Se trata de un análisis que se fija, más bien, en los aspectos económicos de la secesión, en concreto, en el aumento o disminución del bienestar, aunque no se limita a ellos. La decisión del electorado depende de su percepción de los méritos de las distintas alternativas, que, a su vez, dependen de la información recibida. Como la información del electorado es, deliberadamente, un tanto imprecisa, el resultado puede ser ineficiente en el sentido de que puede darse la secesión incluso en el caso de que los mutuos beneficios de permanecer juntos sean mayores que los beneficios de la separación. Para una comunidad internacional preocupada con las secesiones de bienestar decreciente, la exigencia de un apoyo a las reivindicaciones separatistas a través del referéndum puede no ser suficiente (Olofsgard, 2004: 807-827). De manera semejante, Coppieters recuerda que un referéndum del territorio secesionista no es necesariamente reconocido como medio legítimo para medir el grado de apoyo popular a la independencia y puede no ser aceptado internacionalmente, si la limpieza étnica ha decidido su resultado. Incluso, con todos los derecho respetados, el referéndum es un procedimiento problemático, ya que se basa en el supuesto de que una parte de la población pueda expresar su opinión sobre el futuro del Estado. Si a esto se añade la idea de que el referéndum expresa un derecho intrínseco a la secesión unilateral, no ha de extrañar que se defienda que lo relativo a una secesión deba ser sometido al criterio de toda la población del Estado. Cuando, por otra parte, el referéndum es parte de un procedimiento legal complejo (v. g. negociaciones), deja de ser la expresión de un derecho a la secesión unilateral (Coppieters, 2003: 260-269). 
También Norman considera que los teóricos de la elección no responden convincentemente a estas críticas y a otras que él mismo sugiere como las dudas sobre la utilidad del consentimiento para justificar los Estados o que la autonomía individual necesariamente aumente con la decisión colectiva sobre las fronteras del Estado; o la preocupación por las consecuencias antidemocráticas e injustas de la secesión, o por el destino de las minorías dentro de los nuevos Estados o, lo más importante, porque la anarquía secesionista, libre de toda justificación basada en la injusticia previa del Estado, vaya en perjuicio de los valores democrático-liberales (Norman, 1998: 38).

Es curiosa la interpretación que rechaza la teoría democrática por considerarla contraria a la igualdad y a la democracia. Alan Patten se hace eco de algunas de las consecuencias indeseables que la crítica atribuye a la teoría plebiscitaria (proliferación de las crisis secesionistas, violencia, guerras, perversos incentivos, deterioro de la democracia) y, sin entrar en ellas, propone desarrollar una diferente objeción a la teoría plebiscitaria de la secesión a partir de análisis de la nacionalidad en la relación entre democracia y secesión. Patten introduce el concepto de 'reconocimiento' en cuanto condición que afecta a la legitimidad de la secesión. El reconocimiento (con su adecuado desarrollo competencial e institucional y la pertinente reserva de competencias al Estado central) o, en caso contrario, el no reconocimiento de las distintas identidades nacionales en una Estado multinacional legitima o deslegitima la secesión. No es suficiente un mandato democrático para separarse legítimamente de un Estado justo, es decir, cumplidor de sus obligaciones, y, entre ellas, la del 'reconocimiento'. Cuando un Estado reconoce la nacionalidad distinta en un Estado multinacional con su adecuado desarrollo institucional no hay secesión legítima. La decisión democrática no produce, por sí misma, el derecho de secesión. Según esto, la teoría plebiscitaria, que no reconoce tal condición, es excesivamente permisiva, incluso, en los casos más moderados y limitados. Ahora bien, el principio democrático de la igualdad, supuesto que el reconocimiento de un grupo es algo positivo y que esto es así para todos los grupos, exige que las previsiones constitucionales que establezcan el mismo reconocimiento para todos sean valoradas y respetadas. Sin embargo, la teoría plebiscitaria permitiría secesiones que, no sólo no respetan, sino que desmantelan los acuerdos constitucionales que establecen el mismo reconocimiento. La teoría plebiscitaria, de este modo, entraría en conflicto con un reconocimiento igual de los grupos o de las identidades nacionales de una misma comunidad y por ello es rechazable.

Obsérvese que una teoría democrática, la plebiscitaria, es rechazada por su contradicción con el principio democrático de la igualdad. Éste sería el caso de un Estado federal en el que la parte secesionista de una región donde se dan las dos identidades, la estatal y la de una minoría nacional, ganase un referéndum mediante el cual se alterarían las bases constitucionales y la identidad de la minoría nacional sustituiría totalmente a la otra identidad. Un resultado contrario a la igualdad sería fruto, según la teoría plebiscitaria, de 
una decisión de la democracia. Patten considera que sería legítimo en este caso limitar, incluso anular, la autoridad de tales procedimientos particulares con el fin de obtener resultados más iguales, de la misma manera en que se limita o se anula un mandato democrático que pueda suponer, probablemente, violaciones de los derechos. Y, si bien el principio de igualdad debe ser tenido en cuenta para una valoración de la teoría plebiscitaria, también hay que tener en cuenta el argumento de la democracia. El problema se plantea en un territorio donde se dan las dos voluntades y las dos identidades, la secesionista y la unionista. Patten, que se muestra un tanto dubitativo en la decisión de si debe ser el territorio regional o todo el Estado el sujeto decisor sobre la secesión, en último término defiende inequívocamente que la mejor solución para que cada uno se encuentre en su asociación preferida, en el supuesto de un pluralismo identitario (donde caben diversas opciones: identidad estatal nacional, identidad secesionista y participación de las dos identidades), no es aquélla en la que una mayoría obtiene todo y una minoría nada, sino aquélla en la que a cada uno se le garantiza un determinado nivel de pertenencia a su preferida asociación. Y esto es lo que se consigue en un constitucionalismo multinacional. En él se acerca uno al ideal máximo respecto a la autonomía asociativa (Patten, 2002: 558-586, passim).

La insuficiencia de un marco teórico es inseparable del uso de una metodología inadecuada. Y es esto lo que, también, destaca cierto sector de la crítica, que ofrece, además, complementos teóricos y metodológicos. Los análisis plebiscitarios demostrarían o bien la inexistencia de una verdadera metodología por parte de los filósofos o bien que se trata de un método a priori, totalmente inadecuado para estos problemas. Su procedimiento consiste en derivar de los puros principios de la democracia o de la libertad de asociación sus conclusiones, como si determinar las fronteras fuese exactamente igual que escoger a los parlamentarios o a los amigos. Cuando nueve veces de cada diez, dice Norman siguiendo a Horowitz y refiriéndose a los problemas étnicos, las secesiones reproducen nuevos problemas étnicos, no se puede decir que todos los riesgos no se pueden evitar, sino, más bien, que el riesgo es inevitable. Detrás de la teoría de la elección hay una concepción del Estado que lo identifica con una colección de individuos autónomos, es decir, una concepción decimonónica liberal, que, en la actualidad, ni siquiera es defendida por los liberales. El liberalismo actual no es ajeno a las cuestiones de identidad, cemento social, sentido de comunidad y de identidad. Por el contrario, el concepto de Estado de los teóricos de la libre elección acabaría casi con seguridad con el actual sistema de Estados, si fuera asumido por el Derecho Internacional o Constitucional. La mayoría de los Estados se haría pedazos por causa de los movimientos de secesión oportunistas. Norman interpreta la teoría como una contradicción, porque, por un lado, es un desafío a la autoridad del Estado y al sistema de Estados, pero, por otro, es la glorificación del Estado, al defender que todo pueblo es injustamente tratado si no se le permite escoger el Estado al que quiere pertenecer (Norman, 1998: 39). 
También para Patten, que se suma a los teóricos defensores de que la secesión únicamente se justifica cuando existen permanentes violaciones de la 'justicia mínima' por parte del Estado o mínimo reconocimiento, el problema es metodológico, ya que una teoría sobre la secesión, para que tenga relevancia práctica, requiere no sólo determinar principios abstractos normativos, sino decir algo sobre quién tiene la autoridad de decidir sobre las disputas secesionistas, bajo qué normas y procedimientos, su posible codificación o constitucionalización y las posibles consecuencias adversas de la incorporación de algunas propuestas abstractas al derecho internacional y a la práctica (Patten, 2002: 582).

Tal vez sea Bruno Coppieters el que más aporta en la crítica a la teoría del derecho primario. Y lo hace, tanto desde el punto de vista teórico como metodológico. Ambos son insuficientes, por lo que propone como alternativa lo que él llama la 'contextualización'. No se refiere expresamente, como en los demás casos que hemos anotado, a los teóricos del derecho primario a la autodeterminación y a la secesión, pero su planteamiento es aplicable, también, a ellos, porque la debilidad de su argumentación es similar a la de quienes defienden otros criterios, como puede ser el de la autodeterminación nacional, y porque la alternativa metodológica que propone es válida, también, para sustituir la utilizada en la teoría del derecho primario.

Coppieters destaca que entre los temas objeto de análisis en los estudios normativos sobre la ética de la secesión no aparezcan el de la legitimidad del uso de la fuerza para conseguir el Estado independiente o el de la seguridad, con lo que la ética de la secesión y la ética de la guerra pertenecen a campos separados de investigación. Además, el método aplicado es el propio de aplicar un razonamiento deductivo a partir de determinados principios que se usan para enjuiciar la secesión, lo que da lugar a que no se preste suficiente atención a las aportaciones de otras disciplinas. De ahí que otras tendencias hagan un planteamiento distinto que trata de superar la compartimentación y la deducción abstracta. Este planteamiento es el de la contextualización de la secesión, que da lugar a un serie de estudios empíricos, que permiten examinar la validez de los distintos planteamientos normativos habituales. La contextualización de los principios de análisis traslada el foco de la investigación desde la Filosofía política a la Historia, al Derecho Internacional y a las Ciencias sociales sin despreciar las aportaciones de la Filosofía política. La capacidad de la contextualización para abrir nuevas vías de investigación ha de examinarse en torno a los siguientes problemas: el concepto de secesión, las condiciones de legitimidad de una secesión unilateral, la distinción entre nación étnica y nación cívica, la soberanía en un proceso secesionista y el problema de la justificación moral de la guerra. Y esto requiere la utilización de nuevas categorías entre las que destacan la distinción entre secesión, movimientos secesionistas y procesos secesionistas, la interpretación de los conceptos de nación cívica y étnica como tipos ideales al estilo de los conceptos de autoridad de Weber y no como conceptos empíricos, la distinción 
entre soberanía como capacidad de regulación de todos los problemas, incluso los movimientos internacionales de capital, cuestión hoy en franco declive, y la soberanía como autoridad o Derecho del Estado, que tiene plena vigencia y es lo que buscan los secesionistas, los cuales no pretenden crear un nuevo orden internacional sin Estados, sino ser parte del sistema de Estados, y, por último, la unión del tema de la guerra justa con el de la separación unilateral (dada la violencia que acompaña en la mayoría de los casos a la secesión unilateral) de manera que las seis condiciones o principios de la guerra justa -justa causa, rectas intenciones, autoridad legítima, probabilidad de éxito, proporcionalidad, último recurso- se apliquen, también, para analizar la ética de la secesión unilateral. Su aplicación puede dar lugar a resultados muy distintos de los que se derivarían de teorías dogmáticas y de métodos deductivos (Coppieters, 2003, 1-21) ${ }^{9}$.

Este conjunto de críticas quiere decir que la teoría democrática no es capaz de responder a ellas, o lo que es lo mismo, no es capaz de integrarlas en un análisis sistemático coherente. Las teorías plebiscitarias invocan la democracia, pero la democracia actual es democracia liberal y hay que estar atento a que la decisión democrática no vaya en contra de valores liberales, ya que el liberalismo fundamentalmente es Estado de Derecho. Y, en este sentido, si bien hoy en día el término democracia incluye el del liberalismo, no hay que olvidar que originariamente tales conceptos tienen contenidos distintos y obedecen a tradiciones distintas. La fusión de los conceptos democracia y liberalismo no es absoluta ni puede serlo. La suma de todos los contenidos democráticos y liberales en un sistema político llevaría a claras incompatibilidades y contradicciones, como ocurriría, por ejemplo, en el caso de que una decisión democrática mayoritaria negase la libertad religiosa a un grupo de la comunidad política. Democracia y liberalismo, más que fusionarse, van juntos en nuestros sistemas democráticos, limitándose y complementándose mutuamente a través del Derecho positivo. Determinados valores, v. g. la libertad individual liberal, no tienen la misma acogida en la democracia radical. Como es sabido, y Freeman lo recuerda, el liberalismo se define por los valores individuales, la limitación del poder de los gobernantes, independientemente de que sean democráticos o no, los derechos individuales y la protección constitucional de los derechos individuales contra la voluntad popular mayoritaria. En cambio, la democracia es una interpretación de la legitimidad del poder, que considera que el poder pertenece o está en el pueblo, independientemente de que sea liberal o no, y es reacia a limitar el poder de los gobiernos democráticos. Lo más importante en la democracia es la voluntad del pueblo y ésta no tiene necesariamente

${ }^{9}$ Estos instrumentos y criterios son aplicados por diversos autores en los estudios que recoge la obra de Bruno Coppieters a los casos de la Liga Norte en Italia, Córcega, Chipre, Irlanda del Norte, Yugoslavia, Tatarstan, Chechenia, Georgia-Abkhaz, Québec y Taiwán. 
que respetar los derechos individuales. Al liberalismo le preocupa más la protección constitucional de los derechos individuales contra decisiones de mayorías populares, mientras que a la democracia le interesa más que lo relativo a los derechos sea resuelto por procedimientos democráticos. La solución final sobre los derechos en el liberalismo se encomienda a los jueces; la democracia prefiere las asambleas elegidas (Freeman 1999: 362). Ahora bien, en los siglos XIX y XX se produce la convergencia entre liberalismo y democracia, que se mantiene en la actualidad, no obstante la pretensión de algunos de potenciar la democracia a costa de hacer desaparecer el liberalismo. En la democracia liberal, fruto de esta convergencia, «el liberalismo es sobre todo la técnica de los límites del poder del Estado, mientras que la democracia es la entrada del poder popular en el Estado» (Sartori, 2007: 242). Una teoría democrática no puede olvidar esta distinción. Tampoco puede olvidar que un marco teórico democrático de análisis requiere la clara definición del concepto de democracia, cosa que se hace de manera insuficiente en la teoría democrática de la secesión. La democracia liberal no es meramente participación y decisión de los ciudadanos. Esto ni siquiera lo fue en la democracia clásica griega, en la que un conjunto de instituciones permitían la participación y decisión de los ciudadanos, pero, también, de manera esencial, el control del ejercicio del poder (Sabine, 2002: 31-43) ${ }^{10}$. Como dice Dahrendorf, «la democracia es un conjunto de instituciones cuya finalidad es dar legitimidad al ejercicio del poder político proporcionando» y garantizando los cambios sociales y políticos sin violencia, el control de los que ejercen el poder político y la voz del pueblo en el ejercicio del poder (Dahrendorf, 2002: 9-10).

La teoría democrática no demuestra que una 'parte' del poder popular del Estado tenga el derecho moral a separarse del Estado y fundar un nuevo Estado. Y no lo hace por su insuficiencia académica, al margen de la conveniencia o no de la secesión. Es cierto que para algunos la cuestión más fundamental es decidir la comunidad política a la que se va a pertenecer y en cuya arena pública se va participar. Un demócrata no podría aceptar que las fronteras se considerasen cosa sin importancia o el resultado inapelable de la historia. Para un demócrata, las fronteras son una cuestión que decidir democráticamente. Y, como ya se ha dicho y lo señala Canovan, siguiendo a Whelan y Holden, antes de que el pueblo actúe hace falta establecer quién es el pueblo, de manera que la determinación del sujeto 'pueblo' se convierte en la decisión política más fundamental. Pero en la Ciencia Política los teóricos de la democracia parece que no aportan nada sobre la cuestión, incluso alguno llega a decir que tal problema no es, en sí mismo, propio de la teoría democrática. Lo que se da ampliamente por sentado es que, para los objetivos de la democra-

${ }^{10}$ Ver, también, Jean Touchard (2006: 31-48). 
cia, entendida como democracia liberal, cada Estado contiene un pueblo y las fronteras de los Estados se dan por hechas (Canovan, 1996: 17-18).

Lo que Canovan destaca es lo que antes se señalaba, que un elemento que debería integrar la teoría democrática, el de la determinación del sujeto de decisión, queda difusamente descrito. Pero, con ser esto importante, hay algo que no tiene cabida en una lógica democrática y liberal, y es la prioridad que se da a la formación de las fronteras. Lo mismo ocurre en la teoría nacionalista. En mi opinión, lo más importante, políticamente hablando, no es decidir la 'politeia', hoy en día el Estado, a la que se va pertenecer y en la que se va participar, lo que supondría la delimitación de las fronteras, sino el vivir, tanto en lo que afecta al individuo como a la comunidad política, de acuerdo con los valores y principios de la democracia liberal. La forma política y su dimensión territorial no es más que un instrumento institucional histórico para realizar el objetivo último de vivir en libertad e igualdad. Esta comprensión instrumental y finalista de los Estados permite calificarlos de democráticos, cuando su organización y actuación a través de la participación ciudadana siguen los criterios democráticos y conducen a resultados democráticos y liberales. Esto es lo fundamental y las fronteras son un tema secundario que, a pesar de ello, pueden dar lugar a problemas gravísimos, cuando dentro de ellas no se practica la democracia ni se respetan los derechos de las personas. La misma argumentación que desarrolla Rousseau para legitimar únicamente el Estado democrático deja de lado el proceso histórico de formación del Estado. Lo más importante, a lo que dedica su análisis, es la recreación y la refundación del Estado a través de la democracia. Pero, supuesta esta prioridad, donde hay democracia, no cabe la secesión, ni siquiera, siguiendo argumentos plebiscitarios. La conclusión de Habermas, aunque se refiere a la autodeterminación nacional, es aplicable, también, a este caso. Según el autor alemán, uno de los éxitos más notables del Estadonación ha sido la institucionalización de los procesos de autodeterminación democrática a través de la integración política de los ciudadanos. Esto supuesto, y desde el punto de vista normativo, «el presunto 'derecho' a la autodeterminación nacional que ha configurado el nuevo orden europeo después de la Primera Guerra Mundial, y que tanto daño ha causado, es una extravagancia» (Habermas, 2000: 97). De forma aún más rotunda, Habermas afirma que ni siquiera la discriminación de las minorías tiene necesariamente que justificar la alteración de las fronteras de un Estado injusto. Con más razón, lógicamente, se puede decir lo mismo de una mayoría de una parte de un territorio de un Estado que no tiene más razón para la separación que la de su voluntad. Pero, «en la medida que todos los ciudadanos disfrutan de iguales derechos y nadie es discriminado no existe ninguna razón convincente para la separación de la entidad común existente» (Habermas, 1999: 122). La afirmación de Glaser, que dice que poca gente se siente controlando sus destinos en Estados que no cuentan con su consentimiento para su existencia, a pesar de ser democráticos, no aguanta una comprobación empírica. 
Algunos autores, siguiendo rígidamente este argumento, defienden que sólo se justificaría la alteración de las fronteras, es decir, la secesión, en respuesta a una muy grave injusticia, como, por ejemplo, el riesgo de genocidio o la negación permanente de los derechos humanos. Ésta es la tesis de Buchanam, Norman ${ }^{11}$, Orentlicher y otros autores, a la que se suma entre nosotros Ovejero, que se enmarca dentro de las teorías defensoras del derecho reparador o remedial de la injusticia a través de la secesión, interpretando que también la ausencia de la democracia liberal es injusticia. Estas teorías plantean otro problema, que no tiene cabida en este trabajo. Pero, las teorías plebiscitarias, dice el último autor citado, no aportarían nada para garantizar la igualdad democrática, más bien todo lo contrario. Por ello, si no hay ninguna razón moral que justifique la secesión a partir del derecho de asociación, el problema no es el de las fronteras existentes en los Estados democráticos, sino el de su modificación, y esto es lo que habría que justificar (Ovejero, 2006: 16-17, 95-96).

Evidentemente, este planteamiento tiene sentido en lo que se refiere a Estados democráticos, pero son muchos los casos de movimientos secesionistas en Estados dictatoriales. La teoría democrática tiene todavía menos que decir para estos problemas, ni siquiera para el caso de que el movimiento secesionista se desarrollara dentro de Estados dictatoriales, porque la teoría no abarca todos los elementos en juego en la secesión, tales como la paz y el orden internacional, entre otros. Si se sigue el argumento de manera radical, estaría justificada la secesión de los Estados no democráticos para crear, precisamente, la democracia y garantizar los derechos de las personas, que es lo que dice la teoría remedial. Pero no parece que la paz internacional, con la mitad de Estados no democráticos, saldría fortalecida. Sí se puede decir, en cambio, que la secesión de un Estado democrático para formar un Estado no democrático no tiene ninguna justificación moral, aunque alguien se atreva a defender que toda secesión es siempre una victoria de la democracia.

Tiene especial relevancia destacar que la teoría democrática falla desde los cimientos mismos de su Filosofía Política. La distancia de las teorías democráticas con respecto a la realidad y el olvido de una categoría tan importante como el orden contrastan con la afirmación de Wolin de que todo teórico político «ha clasificado el orden como un problema fundamental de su objeto de estudio. Ningún teórico político abogó jamás por una sociedad desordenada, y ningún teórico político ha propuesto jamás la revolución permanente como modo de vida. En su sentido más elemental, el orden ha

\footnotetext{
${ }^{11}$ Norman, que defiende la necesidad de crear adecuadas instituciones para el tratamiento de la secesión dentro del Estado, cuestión que desarrolla en su trabajo de 2003, considera que en ausencia de tales instituciones la aceptación de la teoría de la justa causa en un escenario democrático es lo más aceptable (1998: 56).
} 
implicado una situación de paz y seguridad que hace posible la vida civilizada (...) toda investigación política se dirige, en alguna medida, hacia los factores que favorecen o contrarían el mantenimiento del orden» (Wolin, 1960: 18). Nada de esto aparece en los autores analizados. La secesión de ninguna manera es sometida de forma sistemática a un análisis riguroso de sus implicaciones con el orden tanto dentro del Estado donde se produce, como en el campo internacional, salvo afirmaciones generales de que el desorden no puede ser un compañero fiel de la secesión y, siempre, en relación con la aplicación de un derecho general a la secesión existente.

Es cierto que el hecho de que el tema de la creación de las fronteras no haya encontrado asilo en la Filosofía Política no impide la legitimidad de integrar tal cuestión en el análisis político, pero ha de hacerse desde parámetros académicos, respetuosos con la realidad institucional y con el objeto de lo 'político' creado por la misma Filosofía Política. Este objeto es históricamente cambiante y cambiable, pero no es desdeñable a capricho hasta el punto de que la autodeterminación y secesión puedan ser analizadas al margen de los grandes temas que dan sentido y significado a los fenómenos políticos, como pueden ser el orden, la paz, el poder, la violencia, el Estado, la comunidad internacional, la autoridad, el consenso, el disenso, la libertad o la igualdad. Ni tampoco se pueden desdeñar las instituciones políticas. Son éstas las que «dan coherencia previa a los fenómenos políticos; de ahí que, cuando el filósofo político reflexiona acerca de la sociedad, no se encuentra ante un torbellino de sucesos o actividades inconexos que se precipitan a través de un vacío democriteano, sino ante fenómenos ya dotados de coherencia e interrelaciones» (Wolin, 1960: 17). Por otra parte, la Filosofía no puede operar con categorías o conceptos teóricos totalmente ajenos a cualquier contraste con la realidad empírica, por mucha libertad que se dé al filósofo de ignorar los hechos y de establecer únicamente 'el deber ser' abstracto. A quien no acepte semejante criterio habría que decirle que la secesión es más una cuestión de Ciencia Política y Derecho que de una Filosofía moral o política. Los teóricos plebiscitarios utilizan por separado una Filosofía abstracta de la que concluyen el deber ser indiscutible sobre la secesión, que es limitado con ciertas observaciones de lo que supondría la aplicación dogmática de tal conclusión, pero no hay ninguna integración de la perspectiva teórica y práctica.

Cuando se trata de aplicar la teoría de la asociación política, se observa su prácticamente nula utilidad, como le ocurre a Moore al estudiar el caso de Iraq y, especialmente, el de los kurdos. La autora se ve obligada a reconocer que tiene una aplicación muy poco interesante. El problema de si los kurdos tienen derecho a la secesión se escapa de cualquier análisis basado en la teoría asociativa, porque la realidad social es tan compleja, que desborda la simpleza del planteamiento. Se trata de un claro ejemplo de que la decisión democrática puede dar lugar a un resultado injusto. La teoría puede tener por fundamento lo que la autora, tal vez, de manera excesivamente complacien- 
te, califica de un rico fundamento, pero esta manera substantiva de entender la autonomía individual no resuelve el problema, ya que es imprescindible recurrir a análisis empíricos y a otras disciplinas. Moore, sin mencionarlo, da la razón a Coppieters (Moore, 2006: 60) ${ }^{12}$.

\section{La contribución al Derecho Internacional}

Otra distinta valoración crítica de las teorías de la asociación voluntaria es la que sigue el criterio de la aportación positiva o negativa de tales teorías al desarrollo de una moralidad institucional internacional articulada en un sistema de Derecho Internacional. Es uno de los criterios de Allen Buchanam, para quien la cuestión más urgente que plantea la secesión es la de las condiciones por las que se reconocería a un grupo tener el derecho de secesión como materia de moralidad institucional internacional incluyendo un sistema moralmente defendible de Derecho Internacional. La teoría de la libre asociación da poco de sí para desarrollar una respuesta institucional internacional al problema de la secesión.

Los criterios de valoración de cualquier teoría, según Buchanam, son éstos: carácter progresista y mínimamente realista de la propuesta teórica (es decir, ha de mejorar los valores básicos, especialmente, la protección de los derechos humanos, y ha de ser previsiblemente adoptada en el futuro a través del proceso por el que se elabora en la actualidad el Derecho Internacional, uno de cuyos elementos es su creación a través de los Estados); coherencia con los bien enraizados y moralmente progresistas principios del Derecho Internacional; ausencia de estímulos perversos (tales como socavar los principios del Derecho Internacional, obstaculizar estrategias moralmente progresivas para la solución de conflictos o el logro de resultados como una mayor eficacia en el gobierno o una mayor protección de la libertad individual) y una aceptación moral por parte de una amplia audiencia internacional.

De acuerdo con estos criterios, Buchanam -que defiende una teoría de la secesión basada únicamente en la reparación de las injusticias- interpreta que no es probable que el Derecho Internacional adopte las teorías plebiscitarias, ya que éstas autorizan el desmembramiento de los Estados, incluso el de aquellos que son considerados justos por cumplir las funciones legitimadoras de un Estado, lo que supone una amenaza directa y profunda a la integridad territorial de los Estados. La oposición de los Estados no sería únicamente una cuestión de mero 'interés' estatal, sino de un interés moralmente

${ }^{12} \mathrm{Su}$ idea de que la concepción territorial de la autodeterminación es inadecuada y que no ha lugar a la secesión, cuando los Estados reconocen las identidades nacionales diferentes, sitúa a Moore en clara oposición a la teoría asociativa (Moore:1997: 912-913; 1998: 5; 2006: 78). 
legítimo, ya que el principio de integridad territorial del Estado sirve a algunos de los muchos intereses básicos moralmente legítimos de los individuos, como son su protección física, la preservación de sus derechos, la estabilidad de sus expectativas y la participación en el proceso de gobierno. Tales derechos dependen de la aplicación efectiva de un orden legal, que, a su vez, exige una efectiva jurisdicción y, lógicamente, un territorio claramente definido. Por todo ello, se puede decir que el Estado tiene un 'obligado' interés en mantener su integridad territorial, ya que ella contribuye a realizar tales derechos, así como permite a los ciudadanos influir en la calidad del orden legal. Es esta participación la que exige una alta estabilidad tanto de una efectiva jurisdicción de las leyes como de los miembros del Estado o de la pertenencia al Estado. En la medida en que la integridad territorial ayuda a respaldar la integridad de la participación política, la legitimidad de ésta añade un peso moral al principio de integridad territorial. Ahora bien, Buchanan no omite que este principio puede también ser invocado para apoyar una situación moralmente deficiente. Por ello, el principio en cuestión no puede ser interpretado de una manera absoluta, ya que no permitiría distinguir entre Estados legítimos e ilegítimos, sino de una manera progresiva, que se aplicaría únicamente a los Estados legítimos, entendiendo por ilegítimos los que amenazan la vida de partes importantes de su población mediante políticas de persecución étnica o religiosa, o exhibe un racismo institucional que priva a una proporción importante de población de los derechos básicos económicos y políticos. El cambio de una interpretación absoluta a otra progresiva del principio de integridad territorial sirve a intereses moralmente legítimos, como son los de los individuos y grupos y no los de los Estados, y refleja una actitud normativa superior.

La protección del principio a los Estados legítimos sería un estímulo para que los Estados causantes de injusticias trataran de evitarlas, buscando así la protección que evitara su desmembramiento. Por el contrario, si el derecho internacional reconociese el derecho de secesión basado simplemente en el derecho de asociación, estaría animando a los Estados, incluso justos, a impedir que los grupos se convirtiesen en demandantes del derecho de secesión, lo que daría lugar a la comisión de injusticias. Porque, si como dice Wellman, cualquier grupo territorial que pueda funcionar como un Estado tiene derecho a la secesión, los Estados tratarán de impedir la formación de tales grupos prósperos y bien organizados. Sería dar a los Estados incentivos para fomentar la dependencia económica y política. En el supuesto de que la teoría de la asociación voluntaria fuera aceptada como criterio de reforma del Derecho Internacional, ello iría en contra de lo que muchos, incluidos expertos de Derecho Internacional, ven como una solución en los problemas de secesión, la descentralización. Y no se puede aceptar la preferencia de la secesión sobre la descentralización apoyándose en la idea de que la descentralización daría excesivo peso moral a los intereses de los Estados, porque, en primer lugar, la descentralización tiene su propio atrac- 
tivo moral (promover intereses moralmente legítimos como una más eficiente administración o impedir la excesiva concentración del poder) y, en segundo lugar, tiene el apoyo de un principio fundamental del Derecho Internacional, la integridad de los Estados, que sirve a los intereses legítimos de individuos y grupos.

Lo dicho por Buchanam contra la teoría de Wellman expresamente la extiende a la teoría de Beran considerando que es un estímulo para los Estados evitar la descentralización y, así, impedir la formación de mayorías secesionistas. Estas teorías obrarían negativamente, también, y por los mismos motivos, contra la inmigración, tratando de evitar la formación de potenciales mayorías secesionistas en regiones económicamente viables. Las restricciones a la inmigración serían una de sus consecuencias negativas para evitar que se formasen los grupos políticos, étnicos o culturales secesionistas.

La legitimidad del principio de que la libertad individual debe extenderse a cualquier acción que no perjudique legítimos intereses de otros la extienden los defensores de la asociación individual a cualquier secesión de la que no se deriven consecuencias negativas ni para la región que se separa, ni para el Estado anterior. Buchanam rechaza semejante manera de argumentar, porque, siguiendo su razonamiento, pueden derivarse perjuicios inaceptables no tanto de la aplicación de tal supuesto derecho, sino de las reacciones estratégicas por parte de otros, es decir, por parte de los Estados interesados en impedir la formación de las condiciones para ejercer el supuesto derecho. Su reconocimiento por el Derecho Internacional crearía un incentivo más para impedir que otros pudiesen estar en posición de satisfacer las condiciones para el cumplimiento de las acciones legítimas. Los daños, pues, vendrían de las acciones de los Estados reactivos a los incentivos creados por la aceptación de esta concepción del Derecho como un principio para el orden institucional internacional.

En resumen, Buchanam defiende que las teorías plebiscitarias, por su falta de focalización institucional, fracasan en apreciar la importancia de los Estados, tanto en la práctica como moralmente. Son deficientes de acuerdo con el criterio de un mínimo realismo, no son consistentes con los moralmente progresivos principios del Derecho Internacional y crean perversos incentivos. Al no tomar en serio las consideraciones institucionales, tales teorías tienen poco valor en cuanto guías para desarrollar respuestas internacionales más humanas y efectivas ante los conflictos secesionistas. Se trata de teorías ideales, que no se corresponden con un mundo imperfecto y a las que resulta irrelevante el hecho de que los intentos de aplicar sus principios creen incentivos malos o sean rechazados por Estados interesados en impedir violaciones de los derechos humanos que puedan surgir de hacer sus fronteras mucho menos resistentes al cambio. «Una teoría moral de las instituciones -concluye Buchanam- para un mundo tan radicalmente diferente de nuestro mundo, no sólo como es, sino como probablemente siempre será, 
no puede proporcionar una guía valiosa para mejorar nuestras instituciones» (Buchanam, 1998, a:227-228; 239-253) 13.

Las conclusiones de Buchanam sobre la filosofía política guardan parecido con el criterio de Tomuschat de que la mayor parte de la ciencia política permanece asombrosamente en el mundo de las ideas abstractas. Su inquietud, se podría decir, consiste en analizar si las reivindicaciones de secesión se pueden interpretar como una consecuencia directa de los valores de la democracia, dejando prácticamente de lado el análisis de las perturbaciones que acompañan a los procesos reales de secesión. A falta de consentimiento entre las dos partes, el recurso a los métodos violentos se hace casi constante, y es esta razón, por sí sola, la que hay que sopesar para dar un juicio definitivo sobre la secesión (Tomuschat, 2006: 25-26).

\section{Filosofía Política y Derecho Internacional}

Los pronósticos de Buchanam de momento se van cumpliendo. La Filosofía Política está muy lejos del Derecho Internacional, de manera que al generoso reconocimiento de razones morales a la separación unilateral de la Filosofía Política responde un raquítico reconocimiento del Derecho Internacional. Las teorías democráticas son de imposible encaje en el actual Derecho Internacional y en el Derecho Constitucional, aunque no falta algún autor, como no podía ser menos, que mantenga lo contrario. La inestabilidad potencial de la aplicación del principio de la autodeterminación tanto en el orden internacional como nacional se convertiría en explosiva y caótica al tener que aplicarse el principio de concurrencia, es decir, que la teoría debería aplicarse en todos los casos, en un infinito descenso, de territorios cada vez más pequeños, en los que una mayoría de ciudadanos quisiera separarse (Courtois, 2004: 815.816) ${ }^{14}$.

${ }^{13}$ El rechazo de la teoría democrática y, en concreto, de los argumentos de Philpott y Copp, en Buchanam (1998 b: 14-33). Una explicación de su teoría sobre la autodeterminación en Buchanam (1992: 347-365, principalmente, 353-358, y en el trabajo citado anteriormente en el texto, 231-233).

${ }^{14}$ Courtois rechaza hasta su carácter democrático desde una concepción deliberativa de la democracia, ya que reduce el proceso democrático a una estrategia regulada procedimentalmente y la autonomía de los ciudadanos a una democracia de elección de programas y partidos. La democracia es algo más -y ésta es la interpretación de la llamada democracia deliberativa- que consiste en una discusión pública en los foros formales (parlamentos y tribunales) y en los informales (sociedad civil), donde han de participar, además de los representantes políticos, los ciudadanos en temas relativos a los programas políticos y las leyes. La democracia no es sólo defensa de los intereses individuales, sino modos de argumentar y razonar en condiciones de reciprocidad y de mutuo respeto. La democracia no es sólo voluntad e interés, sino participación activa y responsable, reflexión crítica sobre las razones morales de los programas y de las decisiones y moderación pública en los debates (Courtois, 2004: 816). 
Para Rubin, que no puede ocultar su pesimismo ante el fenómeno de la secesión, donde es difícil llegar a un acuerdo en el derecho positivo, donde la justicia es un término inconsistente, carente de satisfacción universal, y donde la estabilidad política, esencial para conseguir un orden legal, un orden económico y orden moral estables, puede hacerse imposible por la fuerza de los sentimientos, está claro que, a pesar de lo que dicen algunos tratados, no cabe hablar de un derecho a la autodeterminación y a la secesión desde el punto de vista del Derecho Internacional positivo. Los tratados, se podría decir 'disidentes', se refieren al supuesto derecho en el sentido de principio moral o político (Rubin, 2000: 269-270).

El derecho de autodeterminación, entendido como un mismo derecho con dos vertientes, interna y externa, puede dar lugar, según el Derecho Internacional, a la creación de nuevos Estados, como ha ocurrido con su aplicación en la descolonización y en el contexto de foreign rule. Pero, el derecho de autodeterminación está reconocido por el Derecho Internacional a los 'pueblos' y, si bien es cierto que algunos autores, más el Tribunal Supremo de Canadá ${ }^{15}$, interpretan que un 'pueblo' puede ser una parte de la población

${ }^{15}$ Ver, por ejemplo, Clapham, (2006, 46-64); Dugard y Raic (2006, 94-137) y Dictamen del Tribunal Supremo del Canadá sobre la secesión de Québec de 20 de agosto de 1998, Reference re Secession of Quebec, (1998) 2.S.C.R. 217. Aunque no pertenece al tema de este artículo, bien merece destacar la interpretación de Kohen de la supuesta obligación, según el Tribunal, de negociar entre las autoridades federales de Canadá y las provinciales de Québec, ante la inexistencia de un derecho a la secesión unilateral de Québec tanto en el Derecho interno canadiense como en el Derecho Internacional, una posible modificación de la Constitución canadiense que permitiese la separación de Québec, si ésa fuera la clara voluntad de la población de Québec. Según el Tribunal, existe la obligación de negociar entre las partes, pero el Derecho no impone el resultado de la negociación. La interpretación de Kohen añade que, si el Derecho interno no obliga al Gobierno central a negociar y tampoco lo hace el Derecho Internacional, ningún derecho humano ni principio alguno democrático puede imponer a un Estado la obligación de negociar su división. Otra cosa es que la negativa de un gobierno a tratar una cuestión democráticamente planteada pueda causar un impacto importante en terceros Estados (Kohen, 2006: 18). Al argumento de Kohen se puede añadir que toda Constitución, entendida como norma jurídica fundamental, es un conjunto de normas jurídicas a partir de valores y principios, unas veces, expresamente recogidos y, otras, tácitamente. Las normas jurídicas que concretan y aplican valores y principios constitucionales no son la única forma de especificación de tales valores y principios, pero lo que se debe aplicar por parte de los órganos del Estado no es el principio, sin hacer caso de la norma, sino la norma, cuya interpretación, eso sí, puede ser clarificada mediante el recurso al principio o valor que trata de realizar. Los valores y principios constitucionales pueden dar lugar a otro tipo de normas, pero para ello hay que reformar la Constitución. Por ejemplo, si la Constitución establece el principio y valor de la democracia, la norma jurídica puede concretar ese principio en distintas formas de democracia, pero, si impone taxativamente la práctica de la democracia representativa y excluye la democracia directa, no cabe en nombre del principio de la democracia incumplir la obligación de practicar la democracia representativa y aplicar la democracia directa. Esto supondría aceptar que la Constitución establece dos fuentes de Derecho Constitucional y que los órganos del Estado pueden 
de un Estado, la práctica del Derecho Internacional, por su parte, entiende por pueblo únicamente al pueblo del Estado, de manera que sólo hay un pueblo en cada Estado, y sólo estos pueblos tienen el derecho de autodeterminación. Otras categorías, las minorías y los pueblos indígenas, no son más que partes del único pueblo del Estado con sus derechos correspondientes y distintos de los del 'pueblo'. Por definición, una minoría no puede ser más que parte de un grupo más amplio. De ahí la importancia que tiene que las N.U. reconozcan que una comunidad concreta constituye un pueblo (Kohen, 2006: 9; Spencer, 1998: 24; Canovan, 1996: 18).

Esto no quiere decir que el Derecho Internacional no vaya regulando, cada vez más, la secesión (otra cosa sería afirmar, además, que ello se debe a la influencia de la Filosofía Política), haciéndose cada vez más intervencionista en esta materia. En unas ocasiones, porque impide la secesión cuando las acciones secesionistas violan los principios fundamentales del Derecho Internacional, como es el caso de la creación de una entidad independiente por medio del uso de la fuerza de otro Estado o cuando la secesión basada en la fuerza se considera una amenaza para la paz y seguridad internacionales. En otras ocasiones, porque el Derecho Internacional autoriza la secesión. Esto ocurre en el caso de un territorio incorporado por la Asamblea General de las N.U. a un Estado bajo condiciones que no son respetadas por el Estado (el caso de Eritrea) o, también, con entidades ilegalmente incorporadas a un Estado como ocurrió con los países bálticos en relación con la Unión Soviética. Este apoyo del Derecho internacional a la secesión puede, también, producirse en el caso de que un Estado, que reconoce el derecho de secesión en su propio ordenamiento, no lo respete, abriendo, así, la vía a la secesión a través del Derecho Internacional. Ahora bien, sería un error pensar que fuera de estos casos la prohibición es la norma del Derecho Internacional. Es cierto que los intentos de secesión basados en la fuerza tienen una alta posibilidad de ser considerados amenazas a la paz y a la seguridad internacionales, pero ninguna norma internacional prohíbe a un movimiento buscar la secesión por otros medios distintos al de la violencia (Kohen, 2006:1920). Más bien, cabe decir, que la secesión sigue siendo un fenómeno básicamente no regulado por el Derecho Internacional. Y, si bien es cierto que el principio de no intervención favorece a la autoridad central del Estado, no se puede deducir de ahí que toda secesión viola el principio de integridad territorial, ya que tal principio no se aplica más que en las relaciones internacionales y no dentro del Estado. Por tanto, el hecho de que la creación de un Estado se deba a la secesión no afecta a su legal existencia desde el punto de

escoger ad libitum la que les parezca mejor para solucionar los problemas. El paso de una normativa jurídica constitucional a otra requiere la reforma de la Constitución y esto no es materia de negociación entre un Estado central y una Provincia, sino competencia del poder constituyente constituido, que no es otro que el pueblo y, en este caso, el pueblo canadiense. 
vista internacional, una vez que el hecho primario, el de efectividad del Estado, se haya confirmado (Abi-Saab, 2006: 474).

Estos casos, de todos modos, poco tienen que ver con las teorías, que son objeto de análisis en este trabajo. Más cercanía existe entre las teorías que, tanto en la Filosofía Política como en el Derecho Internacional, invocan el argumento de la justicia reparadora o remedial. Aunque esto queda fuera del objetivo de este artículo, baste decir que si bien los autores discrepan en lo relativo a si el Derecho Internacional reconoce el derecho de secesión remedial en el caso de minorías a las que se niegan los derechos políticos, se muestran más coincidentes en la conveniencia de que el Derecho Internacional incorpore criterios normativos a este respecto o que, al menos, la comunidad internacional, la ONU o el Consejo de Seguridad tengan una mayor participación. Pero el argumento que aducen, cosa que otros lo rechazan tajantemente, no es el de las teorías democráticas, sino el de las teorías reparadoras de las injusticias cometidas por los Estados, especialmente, sobre las minorías étnicas ${ }^{16}$. Detrás de este pretendido recurso está el argumento de que la secesión no es una cuestión que únicamente afecte al Estado y a los separatistas, sino también a la comunidad internacional. No obstante, como advierte Buchanam, el problema de que el Derecho Internacional reconozca la secesión no es sólo una cuestión de contenido, sino de compatibilidad con otros principios internacionales, de tipo de proceso institucional y de incentivos que pueda crear (Buchanam, 2003: 2).

Esta referencia al Derecho Internacional no quiere decir que todos los críticos con las teorías plebiscitarias recogidos en este trabajo se remitan a él buscando una alternativa a la secesión unilateral. Las propuestas son variadas y, además de la internacional, se defienden la regulación constitucional, otros modelos de autodeterminación -autonomía, autogobierno, federalismo-, el derecho de autodeterminación entendido como derecho procedimental, constitucionalismo multinacional o, incluso, asociaciones culturales no territoriales tal como lo hace Gellner (1998: 190) o, como se ha visto, lo propone Bishai (1997: 913).

En la línea de confiar en el Derecho Internacional, Orentlicher ha destacado que la solución a los problemas separatistas no está en acuerdos de política interna, sino en la comunidad internacional, donde la secesión puede ser justificada a la luz de los principios democráticos en casos excepcionales, como remedio a injusticias sufridas y con las garantías de las nuevas minorías. Ahora bien, que la secesión sea justificable por principios democráticos y de manera excepcional no debe impedir explicar por qué tales princi-

${ }^{16}$ Kohen se opone a los autores que defienden que el Derecho Internacional acepta la secesión remedial o reparadora como último recurso (Kohen, 2006: 10). Ver sobre este tema, además de los trabajos ya citados de los autores Kohen, Clapham, Dugard y Raic, Buchanam (2003: 1-5), Orentlicher (2003 a: 20.25.39), Orentlicher (2003 b: 81.82), Horowitz (2003: 71-73), Patten, (2002: 582) y Tomuschat (2006: 45). 
pios generalmente refutan las reivindicaciones separatistas. Pero no hay que hacer el avestruz pensando que, si se ignora el problema de la secesión, se evita echar más leña al fuego separatista, dice Orentlicher. La cuestión debe ser analizada, porque, de lo contrario, serán los separatistas los que llenen el vacío conceptual (Orentlicher, 2003, b: 81-82). Habría que añadir a esta última afirmación que los secesionistas no tienen vacíos que llenar. Otra cosa es que lo hayan conseguido con sistemas de creencias ideológicos y no con criterios académicos.

Horowitz, por su parte, critica la alternativa internacional y defiende que la secesión casi siempre reproduce los mismos problemas que trata de resolver, especialmente en los casos de minorías étnicas, ya que toda separación normalmente incluye minorías étnicas, coincidiendo en esto con los criterios de Moore. Pero el problema es el de las garantías para las nuevas minorías, ya que, si la comunidad internacional podría garantizarles sus derechos dentro de los nuevos Estados, no se ve por qué no podría hacer lo mismo en los Estados actuales y evitar así la secesión. Es decir, viendo el argumento al revés, Horowitz defiende que si la comunidad internacional no garantiza los derechos de las minorías en los Estados actuales, por qué esperar que lo haga dentro de los nuevos Estados. La explicación de que los Estados creados por secesión serán más influenciables por la comunidad internacional que los Estados actuales es una afirmación gratuita. Por otra parte, el Derecho Internacional tiene una relación muy tenue con el gobierno democrático. Tanto es así que la valoración del derecho al gobierno democrático pondría en peligro la universalidad del Derecho Internacional. No hay que olvidar que hay casi tantos gobiernos autoritarios como democráticos y que los Estados son los principales sujetos del Derecho Internacional, por lo que la secesión, que es un movimiento antiestatal, pondría en peligro al Derecho Internacional mismo. Horowitz piensa en soluciones dentro de los Estados actuales a través de políticas de incentivos con una actitud claramente escéptica ante la Comunidad Internacional y el Derecho Internacional (Horowitz, 2003: 50-76, principalmente, 71-73; Buchanam, 2003: 4-5) ${ }^{17}$.

En la perspectiva de lo poco que la Filosofía Política ha contribuido al desarrollo del Derecho Internacional, Klabbers enfría ambos planteamientos con su reflexión sobre la reconceptualización que se ha producido a partir de 1970 acerca del derecho de autodeterminación. Han sido los tribunales los

${ }^{17}$ En Macedo y Buchanam (2003: 6.11-14), se hace referencia a autores que optan por soluciones dentro de los Estados, sean de tipo autonómico (Jacob Levy, M. Moore, que también lo hace, esta última, en trabajos recogidos en la bibliografía), o de constitucionalización de la secesión para casos atípicos (Norman) o constitucionalización a través del mito de la refundación (Marc E. Brandon). Weinstock (2001:202-203) propone la constitucionalización del derecho de secesión para controlar de manera más manejable los procesos de secesión. 
que han realizado esta labor. Ante la imposibilidad de construir el derecho de autodeterminación como derecho de las colonias a la independencia, éste ha evolucionado hacia un derecho de los pueblos a tomar parte en las decisiones que les afecten. Es decir, determinadas entidades tendrían derecho a que su posición se tomara en cuenta cuando se va a decidir su futuro. El derecho de autodeterminación no equivaldría a derecho de secesión, ni siquiera a derecho a la autonomía o al autogobierno. Sería un derecho procedimental, el derecho a ser oído y ser tomado seriamente en cuenta, sin que esto signifique capacidad de veto. Según esto, la teoría de la autodeterminación debe centrarse no sobre una norma creadora de derechos substantivos judicialmente ejecutables, sino como un haz de derechos procedimentales. Esto tiene la ventaja añadida de romper la conexión entre autodeterminación y territorio. Klabbers afirma que, desde el punto de vista filosófico, no existe justificación para limitar la autodeterminación a unidades territoriales. Sin embargo, su comprensión como derecho procedimental permitiría aplicarla a grupos que no son territoriales, tales como iglesias, clases sociales o pueblos dispersos. El Tribunal Internacional de Justicia y otros tribunales habrían caído en la cuenta de que lo imposible es imposible y, así, en lugar de dar aprobación judicial a la ruptura de los Estados, han elaborado un nuevo modo de entender la autodeterminación, es decir, como un principio legal o una norma de procedimiento. Se trata de una aportación al pensamiento político convertir el derecho de autodeterminación en una garantía procesal. Ello entra dentro de una teoría política republicana, donde la definición de los valores de una comunidad política deben hacerse mediante un debate político sin trabas (Klabbers, 2006: 189.202203. 205-206).

\section{CONCLUSIONES}

$\left.1 .^{a}\right)$ No cabe afirmar que la teoría plebiscitaria haya dado razones morales sólidas que avalen el derecho moral de secesión de los grupos, cuya mayoría quiera separarse de un Estado justo, salvo en el mundo de la abstracción y de la fantasía; esto es sostenible, incluso, en el caso de los autores menos radicales, que con sus condiciones y restricciones a la tesis inicial la hacen prácticamente inaplicable.

2. $\left.{ }^{a}\right)$ La razón fundamental de este fracaso es de índole teórica y metodológica, donde destacan a) el uso indebido de categorías conceptuales, la utilización de la democracia como único criterio moral, la exclusión de categorías y valores tanto de la Filosofía Política como del liberalismo (v. g. orden, poder, paz internacional, seguridad, derechos individuales), el supuesto de un falso concepto de Estado democrático y liberal, el deficiente concepto de legitimidad y autoridad del Estado, la identificación de toda asociación política con el territorio, la infravaloración del papel positivo de los 
Estados democráticos en la realización de los derechos fundamentales de los ciudadanos y la tendencia a presentarlos como sujetos de intereses ajenos a los de los individuos y grupos sociales, la artificiosidad del concepto de autodeterminación individual desligado de la realidad basada en la cooperación y colaboración, la simplificación de la realidad identitaria de las personas, fruto de una defectuosa teoría sobre la identidad con su consiguiente deficiente observación empírica, o la exclusión de la teoría de las minorías dispersas, y b) el uso de un método de análisis meramente deductivo, ajeno a las exigencias tanto institucionales como a los análisis teóricos y empíricos de otras ciencias, del que resulta, como consecuencia de un deficiente marco teórico, un inadecuado perfil del objeto de análisis.

3. $\left.{ }^{a}\right)$ Otras razones de las deficiencias de la teoría normativa democrática son la indeterminación del sujeto territorial de la autodeterminación, así como del contenido de la pregunta en el referéndum, y la utilización del término mayoría sin ninguna especificación.

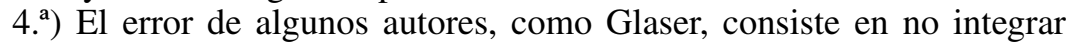
dentro de la teoría las bien fundadas condiciones que les llevan a negar la aplicación del derecho a la secesión; si lo hicieran, no podrían concluir el derecho general a la secesión; la violencia que impide aplicar el derecho, impide, también, justificar previamente el derecho; es el mismo error metodológico que cometen las teorías de la autodeterminación nacional.

5. a) La conclusión del derecho general a la secesión no es fruto de la aplicación de una teoría, sino, en todo caso, de un silogismo; hay más semejanza entre la teoría democrática y un silogismo escolástico que entre aquélla y una teoría científica.

\section{REFERENCIAS BIBLIOGRÁFICAS}

ABI-SAAB, Georges (2006): «Conclusions», en Secession. International Law Perspectives; Kohen, Marcelo G., ed., Cambridge: University Press, pp. 470-476.

BARRY, Brian (2001): «Culture and Equality», Cambridge U.P, Cambridge. - (1997): «La justicia como imparcialidad», Paidós, Barcelona, 1997.

Beobide, Ignacio M. ${ }^{a}$ (2003): «Prensa y Nacionalismo vasco. El discurso de legitimación nacionalista», Universidad de Deusto, Bilbao.

BERAN, Harry (1998): «A democratic theory of political self-determination for a new world order», en Lehning P.B., ed., Theories of secession, Routledge, Londres y Nueva York, pp. 32-59.

BIRCH, Anthony H. (1989): «Nationalism and national integration», Unwin Hyman, Londres.

BishaI, Linda, (1998): «Altered states. Secession and the problems of liberal theory», en Lehning P.B., ed, Theories of secession, Routledge, Londres y Nueva York, pp. 92-110. 
Buchanam, Allen (2003, a): «Introduction», en Secession and self-determination, Macedo Sthefen y Buchanam Allen, eds., New York University Press, Nueva York y Londres, pp. 1-15.

- (2003, b): «The Quebec Secession Issue: Democracy, Minority Rights, and the Rule of Law», en Secession and self-determination, Macedo Sthefen y Buchanam Allen, eds., New York University Press, Nueva York y Londres, pp. 238-271.

- $(1998, a)$ : «The international institutional dimension of secession», en Lehning P.B., eds., Theories of secession, Routledge, Londres y Nueva York, pp. 227-256.

- (1998, b): «Democracy and Secession», en National Self-Determination and Secession, M. Moore, ed., Oxford, Oxford University Press.

- (1992): «Self-Determination and The Right to Secede», en Journal of International Affairs, vol. 45/n. ${ }^{\circ}$ 2. Winter, pp. 347-365.

- (1991): «Secession: The Morality of Political Divorce From Fort Sumter to Lithuania and Quebec», Boulder CO, Westview Press, pp. 27-80.

CANEY, Simon (1998): «National self-determination and national secession. Individualist and communitarian approaches», en Lehning, P.B. ed., Theories of secession, Routledge, Londres y Nueva York, pp. 151-181.

Canovan, Margaret (1996): «Nationhood and Political Theory», Cheltenham, UK- Northampton, MA, USA.

ClaPhAM, Andrew (2006): «Secession, terrorism and de right of self-determination», en Koen, M.G., ed., Secession. International Law Perspectives, Cambridge, University Press, pp. 46-64.

CoPP, David (1997): «Democracy and Communal Self-Determination», en The morality of nationalism, R. Ckim y J. McMahan, eds., Oxford, OU Press, pp. 277-300.

COPPIETERS, Bruno (2003): «Introduction» y «Conclusion», en Contextualizing Secession. Normative Studies in Comparative Perspective, eds. Bruno Coppieters y Richard Sakwa, Oxford University Press, pp. 1-21, 252279.

CourTols, Stephane (2004): «Democratie deliberative et secession», Canadian Journal of Political Science/Revue canadienne de science politique, 37:4 (December/décembre), 811-838.

DARENHDORF, Ralf (2002): «Después de la democracia. Entrevista de Antonio Polito», Crítica, Barcelona.

DowDING, Keith (1998): «Secession and isolation», en Lehning P.B., ed, Theories of secession, Routledge, Londres y Nueva York, pp. 71-91.

DugARD, J. y RAIC, D. (2006): «The role of recognition in the law and practice of secession», en Kohen, M.G., ed., Secesssion. International Law Perspectives, Cambridge, University Press, pp. 94-137.

FrEEMAN, Michael (1999): «The right to self-determination in international politics: six theories in search of a policy», Review of International Studies, Jul, 25 (3), 335-370. 
GaUtier, David (1994): «Breaking up: an essay on secession», Canadian Journal of Philosophy, vol. 24. n. ${ }^{\circ}$ 3, septiembre, pp. 357-372.

GELLNER, Ernest (1998): Nacionalismo, Ciencias Sociales/Destino, Barcelona. Glaser, Darul J. (2003): «The Rigth to Secession: an Antisecessionist Defense», Political Studies: vol. 51, pp. 369-386.

HABERMAS, Jürgen (2000): La constelación posnacional. Ensayos políticos, Paidós, Barcelona.

- (1999): La inclusión del otro. Estudios de teoría política, Paidós, Barcelona.

Horowitz, Donald L. (2003): «¿A Right to Secede?», Secession and SelfDetermination, eds. Stephen Macedo y Allen Buchanan, Nueva York y Londres, New York University Press, pp. 50-76.

KlabBers, Jan (2006): «The Right to be Taken Seriously: Self-Determination in International Law», Human Rights Quarterly 28, pp. 186-206.

KoHeN, Marcelo G. (2006): «Introduction», en Secession. International Law Perspectives; ed., Kohen, Marcelo G., Cambridge University Press, Nueva York, pp. 1-20.

MARGALIT, Avishai y RAz, Joseph (1990): «National self-determination», The Journal of Philosophy, vol. 87, no. 9, pp. 439-61.

MiLler, David (1997): Sobre la nacionalidad, Paidós, Barcelona.

Moore, Margaret (2006): «The Ethics of Secession and Post invasion Irak», Ethics and International Affairs, Volume (20.1, Spring), pp. 55-78.

- (1998): «Introduction: The Self- Determination Principle and the Ethics of Secession», en M Moore, ed., National Self-Determination and Secession, Oxford, Oxford University Press.

- (1997): «On National Self-Determination», en Political Studies, XLV, 900-913.

NielSEN, K. (1998): «Liberal Nationalism and Secession», en M. Moore (ed), National Self-determination and Secession. Oxford: Oxford University Press, pp. 103-133.

Nielsen, K. (1993): «Secession: the Case of Quebec», Journal of Applied Philosophy, 10 (1), pp. 29-43.

Norman, Wayne (2003): «Domesticating Secession», en Secession and Self-

Determination; eds. Macedo, Stephen y Buchanam Allen, Nueva York y Londres, New York University Press, pp. 193-237.

Norman, Wayne (1998): «The Ethics of Secession as the Regulation of Secessionist Politics», en National Self-determination and Secession; dir., M. Moore, pp. 34-61, Oxford University Press.

OlOFSGARD, Anders (2004): «Secession and Political Extremism: Why Regional Referenda do not Solve the Problem», Journal of the European Economic Association September, 2(5), pp. 805-832.

Orentlicher, Diane F. (2003, a): «International Responses to Separatist Claims: Are Democratic Principles Relevant?», en Secession and SelfDetermination; eds., Macedo, Stephen y Buchanam, Allen, Nueva York y Londres, New York University Press, pp. 19-49. 
- (2003, b): «Democratic Principles and Separatist Claims», en Secession, and Self-Determination; ed. Macedo, Stephen y Buchanam, Allen, Nueva York y Londres, New York University Press, pp. 77-86.

Ovejero LuCAS, Félix (2006): Contra Cromagnón. Nacionalismo, ciudadanía, democracia, Montesinos, Ensayo, Barcelona.

PATtEN, Alan (2002): «Democratic Secession from a Multinational State», Ethics 112 (abril), pp. 558-586.

PhilPOTT, Daniel (1998): «Self-Determination en Practice», en National Self-Determination and Secession; ed. M. Moore, pp. 79-102.

- (1995): «In Defense of Self-Determination», Ethics, vol. 105, Junio, n. ${ }^{\circ} 2$.

Rubin, Alfred P. (2000): «Secession and Self-Determination: A Legal, Moral, and Political Analysis», Stanford Journal of International Law, 36 (2): pp. 253-270, Sum.

SABINE, George H. (2002): Historia de la teoría Política, F.C.E, Madrid, tercera edición en español 1994, sexta reimpresión 2002.

SARTORI, Giovanni (2007): ¿Qué es la democracia?, Taurus, Madrid.

SPENCER, Metta (1998): «When States Divide», en Separatism, Democracy and Disintegration, ed. Spencer M., Oxford, Rowman y Littlefield Publishers.

TOMUSChat, Christian (2006): «Secession and self-determination», en Secession. International Law Perspectives; ed., Kohen, M.G., pp. 23-45.

TOUCHARD, Jean (2006): Historia de las ideas políticas, Tecnos, Madrid, 6. ${ }^{a}$ edición 2006, reimpresión 2007.

Weinstock, Daniel (2001): «Constitutionalizing the Right to Secede», The Journal of Political Philosophy, vol. 9, n. ${ }^{\circ}$ 2, pp. 182-203.

WELLMAN, Christopher (1995): «A defense of self-determination and secession», Philosophy and Public Affaires, vol. 24, n. ${ }^{\circ}$ 2, pp. 142-171.

Wolin, Sheldon S. (1960): Política y perspectiva. Continuidad y cambio en el pensamiento político occidental, Amorrortu, Buenos Aires. 